\title{
The Design Characteristics of Nature-inspired Buildings
}

\author{
Jin Kim¹, Kanggeun Park ${ }^{2, *}$ \\ ${ }^{1}$ Department of Paideia, Sungkyul University, Anyang, South Korea \\ ${ }^{2}$ Department of Architectural Engineering, I’ST Institute, Seoul, South Korea
}

Copyright $@ 2018$ by authors, all rights reserved. Authors agree that this article remains permanently open access under the terms of the Creative Commons Attribution License 4.0 International License

\begin{abstract}
The systems, processes, and organisms optimized for the evolution of nature over several hundred million years have helped designers and architects seeking improved and innovative solutions. Inspired by the shape and function of nature, some architects have created great architectures by finding and applying new design sources from nature's elements. The beautiful and mysterious nature landscape surrounding us not only gives us a new appearance for the four seasons, but also provides the source of new ideas for human. When looking at nature elements such as trees, flowers, animals, and ocean organisms, architects can find unusual perspectives, visually interesting ideas, special structures, creative details and innovative mechanisms. Most modern cities are full of buildings like the shape of supermarkets and boxes, if possible, architects should try to satisfy human emotions with beautiful scenery and natural closeness through environmental architecture. When planning for future cities and constructing new buildings, how to satisfy our yearning for a harmonious interaction with nature, and how the historic characteristics of buildings are shown to be presence. All of these are related to our fundamental human feelings and emotions, can improve holistic interrelationships between buildings and nature for human life. Nature-inspired biomimicry is a way of observing the natural world to find design solutions that may enable us to create the concepts of new building design with sustainable and healthy. This study is to analyze what are nature inspirations for the visual and conception building designs and what are the characteristic of innovative designs and technologies inspired by nature.
\end{abstract}

Keywords New Design Source, Nature-inspired Architecture, Nature-inspired Biomimicry

\section{Introduction}

Nature has been associated together with human history intimately, and humans have developed a culture that gets inspiration from nature. Nature provides new sources that cannot be explained by science with its various and constant change. Nature is creating better the biological structure than the technology developed by humans. In recent years, the researchers have been actively conducted to find various and mysterious aesthetic elements and technology ideas from nature. In the 3.8 billion years of change and evolution, nature learned what is best in our environment, what is most appropriate, and what is the last thing. The Earth is a little over 4.5 billion years old, its oldest materials being 4.3 billion-year-old zircon crystals. The nature-inspired progresses can be classified into the levels of inspiration that are named as visual, conception and computational level by Janine M. Benyus, American nature science writer, an innovation consultant and author. A visual inspiration is well understood the shape of various organisms, and to imitate similarly looking structures and systems. A conception inspiration occurs when scientists applied principles found in nature, and a computational level is inspired by organisms occurring in nature. Recently, many scientists have been studying and imitating nature's design elements in mechanisms, organisms, and biostructure. Biomimetic research aims to solve mankind's problems by understanding and imitating the many mysterious elements of nature. The field of natural inspiration is very important and useful for designers today, and nature provides many designers with creative ideas and limitless inspiration to develop a new design. Architectural building design and system are developing sustainable eco-friendly designs and technologies that inspired by nature. Advanced technology fields focus on biomimicry science for biomimicry robotics and nanotechnology, and industrial technologies by the inter-corporation with biologists, physicists, engineers and designers. As the Earth's crisis is growing due to changes in the Earth's environment, the exhaustion of energy and resources, and the decline in biodiversity, the need for a nature-friendly environmental ecosystem with the coexistence of humans and nature is emphasized. Environment-friendly architecture is about saving energy and resources, and preserving the natural environment and promoting organic linkage for the human health and comfort in design, construction, and maintenance. Eco-architecture is the 
creation of eco-friendly buildings based on scientific knowledge and understanding of natural ecosystems.

The research is necessary for architects to get the new design sources from nature for visual and conceptual design. This study focused on investigating new design buildings inspired by nature, and it will be analyzed the design strategy of famous buildings and technical procedures to create a nature-inspired design. The design characteristics of bio-eco architectures which replicate organisms and mechanisms of nature in order to create an innovative design will be surveyed, then it will be shown how to seek the design processes and how to get new design sources in nature.

\section{Nature and Culture}

\subsection{Nature-inspired Culture}

Landscape in Korea and China has often been closely tied to painting and poetry. Landscape painting and poetry remain popular to the present day. Many landscape painting show the pursuit of a pure depiction of nature. The history can find in master planning and garden design for houses, palaces, and religious complexes. One of important aspect in painting, literature, and philosophy was perceived and valued the landscape. Human has developed civilization and culture through the imitation of nature.
Artists have long been transformed from an imitation of nature to an abstract world that gradually reflects the unknown world. By pursuing the intrinsic of nature, it has sublimated into the art of restoring humanity, and finding the essence of art. Man finds the beauty and mystery of nature in touching and looking at nature. Art is not a mere imitation of nature but a search for human soul through art. When the image in nature is shaped into individual intuition, it is sublimated into art. Oriental thought considered living in harmony with nature as a virtue. The West recognized nature as a subject of inquiry. Man explored phenomena and order that occur in nature. Ecological art is a painting that expresses mainly the function of nature cycle. The phenomenon of ice melting, plant cultivation, wind noise, and nature elements are expressed in painting. The scholars of the Joseon Dynasty(1392-1897) of Korea loved four gentleman plants. It is because the plum, orchid, chrysanthemum, and bamboo resemble a man of their ideal. Plum is the first flower to bloom in cold early spring. The orchid has a noble appearance and a fragrant smell. The chrysanthemum is the flower that overcomes the cold of frost in late autumn. The bamboo, which does not lose its blue color even in winter when the snow is blowing, resembles a nice man. The love of the four wonderful plants was not limited to poetry, but was visualized as a picture.
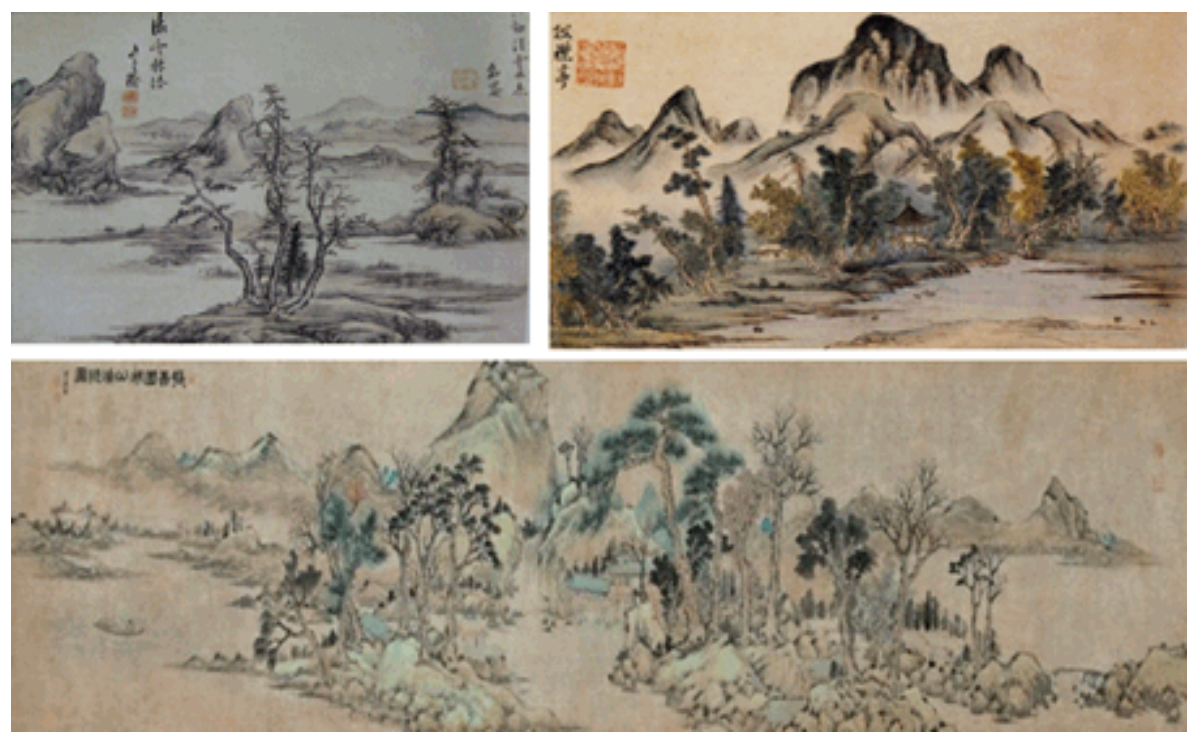

Figure 1. Landscape paintings
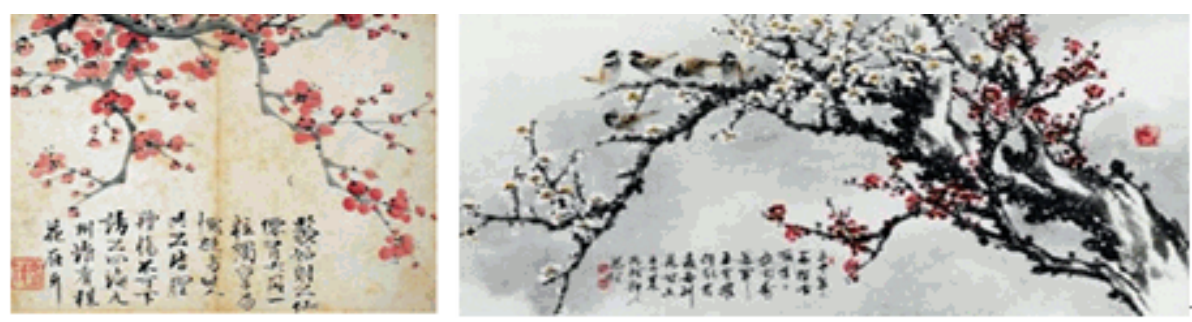

Figure 2. Plum paintings 


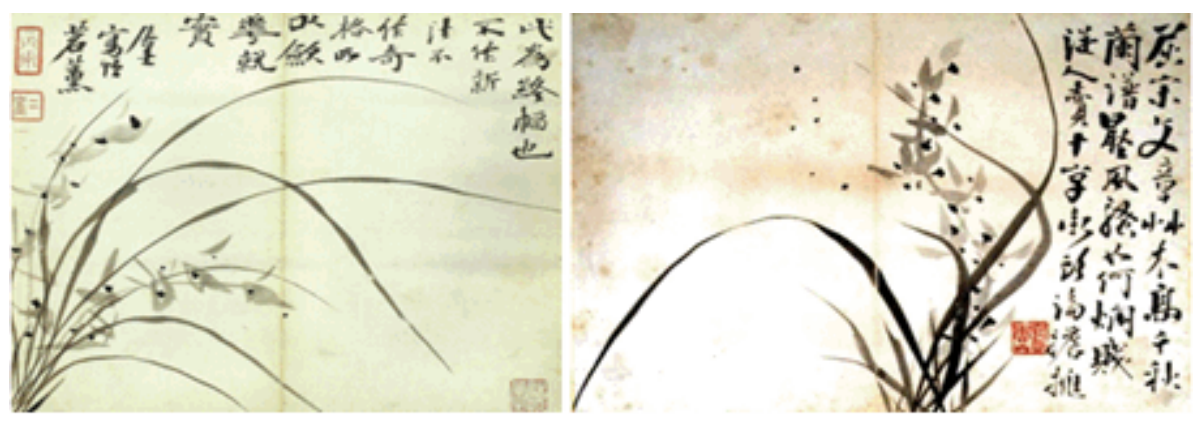

Figure 3. Orchid paintings

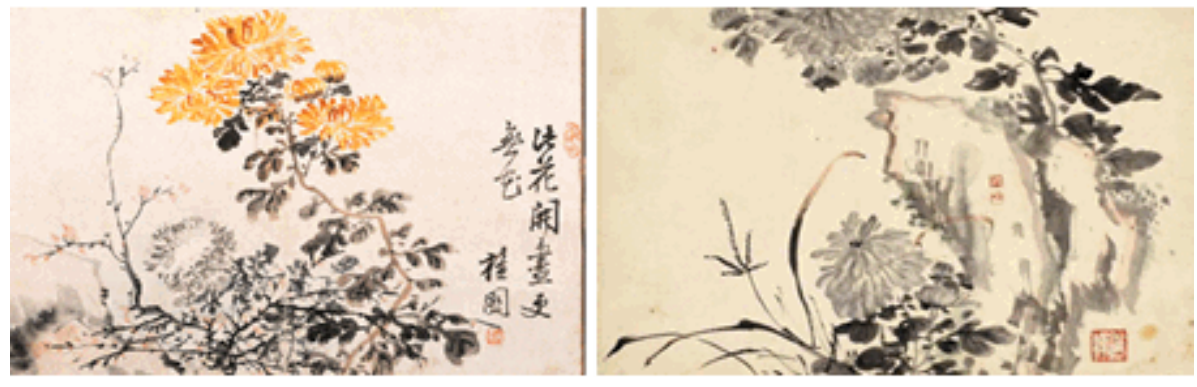

Figure 4. Chrysanthemum paintings

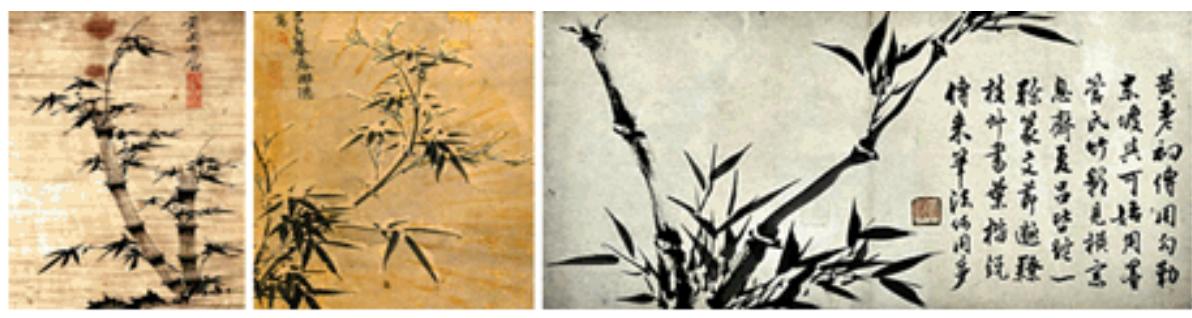

Figure 5. Bamboo paintings

\subsection{Traditional Landscape Theory}

The layout of houses in Korea is based on an oriental landscape geography. The landscape geography is based on the phenomenon of the universe of heaven and earth, and plans to harmonize with the characteristics of the area environment. The basic elements of oriental geography are mountain and water. The land plan was analyzed the landscape of the surrounding mountains, the flow of water, and the contour of land. Many people thought that the situation around the land had an effect on the personality, health, and success of the people living there. Successful people has lived in the site of the best possible environment to continue their success, peoples thought that they would live in a good natural environment and make an ancestral tomb with the best site conditions. As time went on, many people thought that the energy of the surrounding mountains and ground would greatly affect the happiness and success of the local people. A good site for a village was surrounded by mountains in the back of the house, and in front of the house there was a wide land that a river is flowing. This theory is closely related to the monsoon climate conditions of four seasons in Korea. People thought the best place for a woman's womb-like land. Korean traditional houses had a rank according to the status of society in the form of roof. The spaces between women and men were separated. The spaces of father, mother, child and guest were separated. The roof shapes of Korean traditional houses are very similar to the peaks of surrounding mountain.

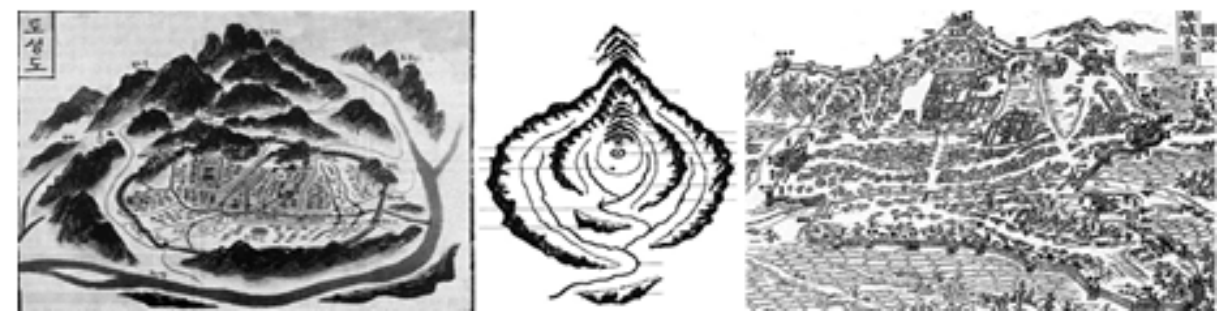

Figure 6. A good site by traditional landscape theory 


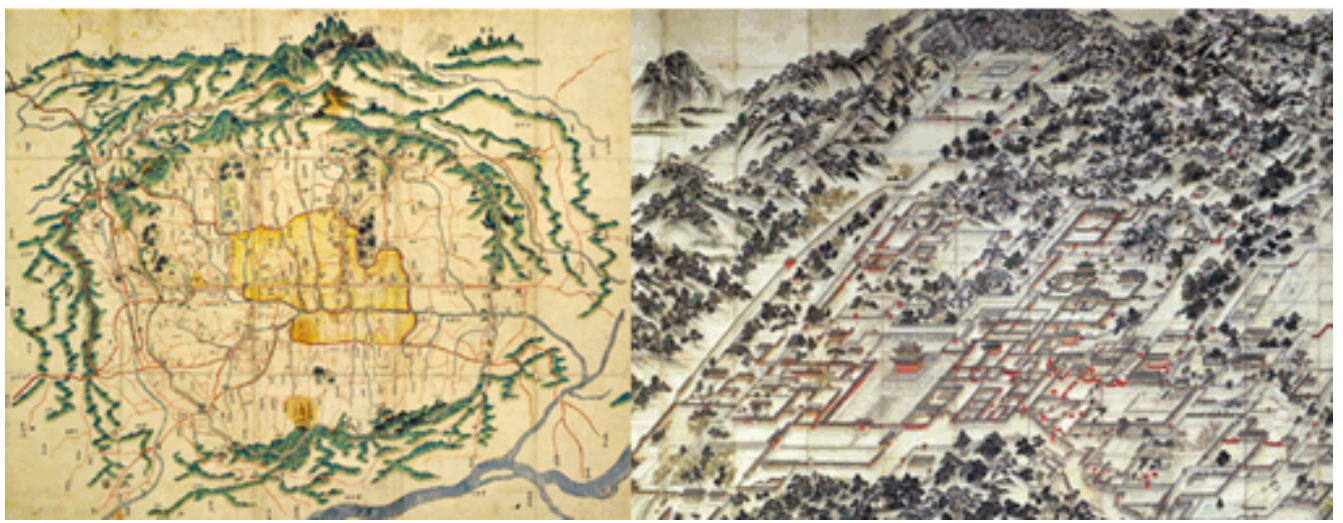

Figure 7. Landscape map of Seoul in Korea (1750)

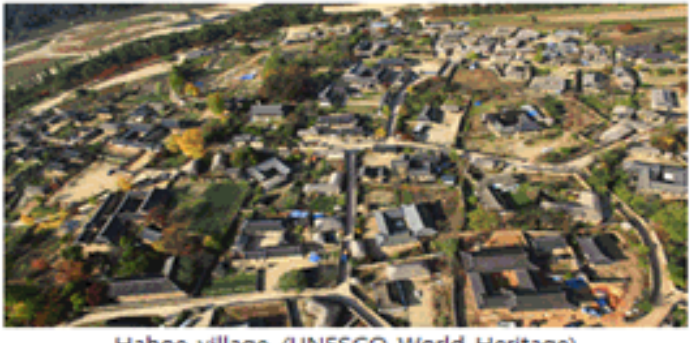

Hahoe village (UNESCO World Heritage)

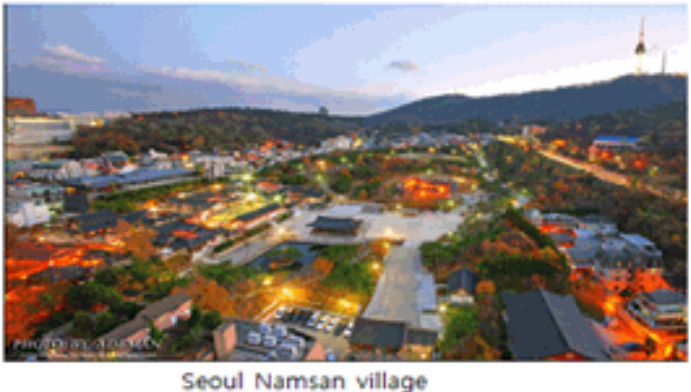

Seoul Namsan village

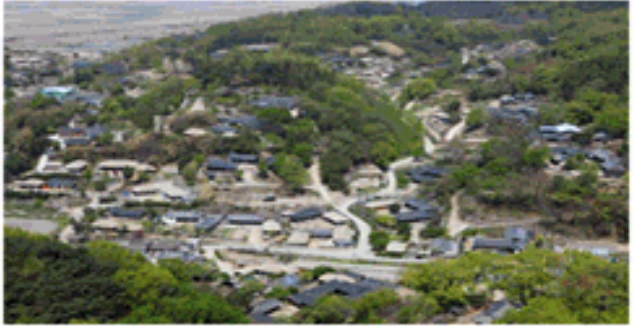

Yangdong village (UNESCO World Heritage)

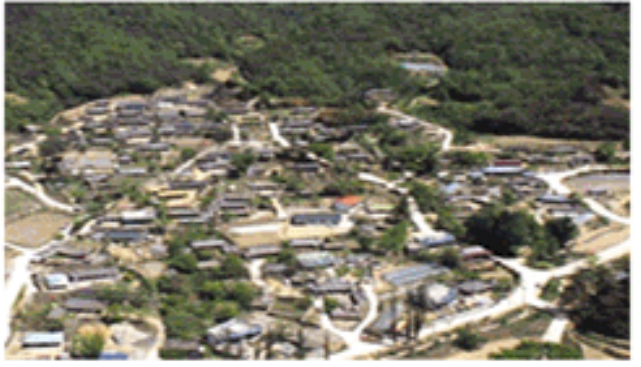

Hangae village

Figure 8. Korean traditional villages

The layout and location of village was sheltered by forested mountains and near a river, and opened agricultural fields. It is reflected the distinctive aristocratic Confucian culture of the Joseon Dynasty (1392-1910). The villages were located to provide both physical and spiritual nourishment from their surrounding landscapes with the best environment condition. The village includes residences of the head families, together with substantial timber framed houses of other clan members, also pavilions, study halls, Confucian academies for learning, the clusters of one story mud-walled and thatched-roofed houses for commoners. The landscapes of mountains, trees and water around the village were celebrated for their beauty by 17 th and 18 th century poets.

\subsection{Korean Traditional Houses}

The layout plan of Korean traditional houses is consists of various spaces with different characteristics such as mother, father, slave, and ancestral area. The layout of the traditional house is basically divided into the fence and it is linked with the surrounding environment organically.
Father's house is overly opened for public space, and there is a large courtyard. It is not intended to be a family space, but to imply that it has meaning in relation to the village. The direction of the houses is looking at the peaks of the stunning South Mountain. The yard of mother is the space for the family, the yard of father is opened and used as a communication place to interact with the villagers. The materials was to build the house that used all natural materials such as wood, soil, paper, rice straw, and roof tiles of black color.

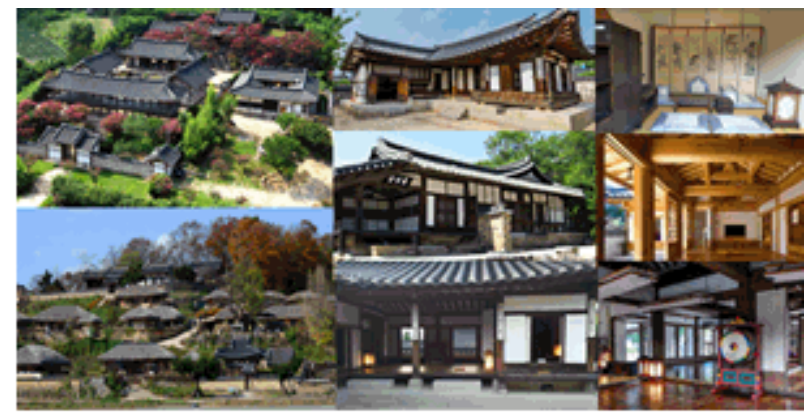

Figure 9. Korean traditional houses 
The roof of rich house is the shape of a mountain, and used roof tiles. The roof where the common people lived is a hill-shaped roof, and the rice straw is mainly used. There is a large courtyard and a small courtyard around the house, a small tea house and pond. In summer, most of the doors were opened so that the entire house was well ventilated. In the winter, the rooms were warmed by passing fire under the floor. The house was designed to be a harmony of nature by adapting to the surrounding environment. The connection between the column and the beam is very sophisticated and decorative structures. In front of the room, a wooden floor with the empty space of under the floor was installed so that it could stay cool in summer. The floor was a completely open space in connection with yard.

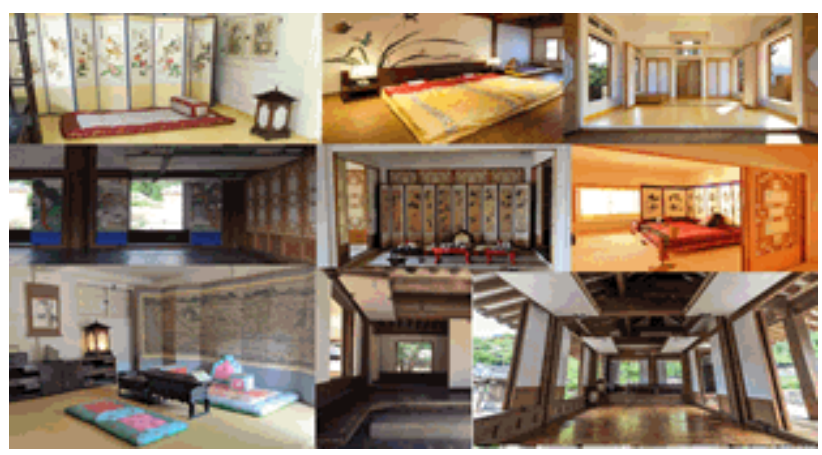

Figure 10. Interior space in Korean traditional houses

The inner space is closed by doors in winter and the door is fully opened in summer. Most lifestyles are a way to live sitting on the floor. In the room, a large picture with painting of plum, orchid, chrysanthemum, bamboo is drawn up to enhance the elegance of the room. The space of between a room and a room were separated by a wooded floor. When the door in the wall is fully opened, it has a sense of unity with the outside nature. On the outside of the house, the beauty of the wood columns and beams are magnificently expressed by connection designs. In the interior, the wooden frames of the column and beam are exposed to the wall, and the beauty of the frames can be appreciated in the inside space of the room.

\section{Eco-friendly Green Building Certification Criteria}

Environmental, social and economic sustainability are important for the plan of city. The universal effort to realize global environmental protection and justice is inevitable. People require a stable job and necessary economic capabilities through continuous economic growth. A social system with equal rights to business ethics should be established. The building has widely direct and indirect relationships with the surrounding environment. During construction, occupancy, remodel, repurposing and demolition, buildings use energy, water and raw materials, generate waste, and release harmful air emissions. This fact has created a green building standard, certification and evaluation system to mitigate the impact of buildings on the natural environment through sustainable design. When construct buildings, architects should respond to designing homes that use less energy than average houses for net zero energy, carbon neutrality, solid, well-insulated wall systems, and high-performance residential design.

Architects are striving to satisfy architectural compliance, structural safety design, environmentally friendly design, long life design and intelligent design when are the design of buildings. However, many buildings in the city are very vulnerable to earthquakes, typhoons, heavy snow, and fire, and causing many problems for the insurance of safety. The life of buildings is only about 40-50 years, the half of human life, and causing serious environmental pollution, urban slums and economic losses. Current design standards are too numerous, complex, and less interdependent. If the design criteria do not set the lowest score for each item, it cannot satisfy the requirement of the desired eco-friendly long-lived intelligent building.

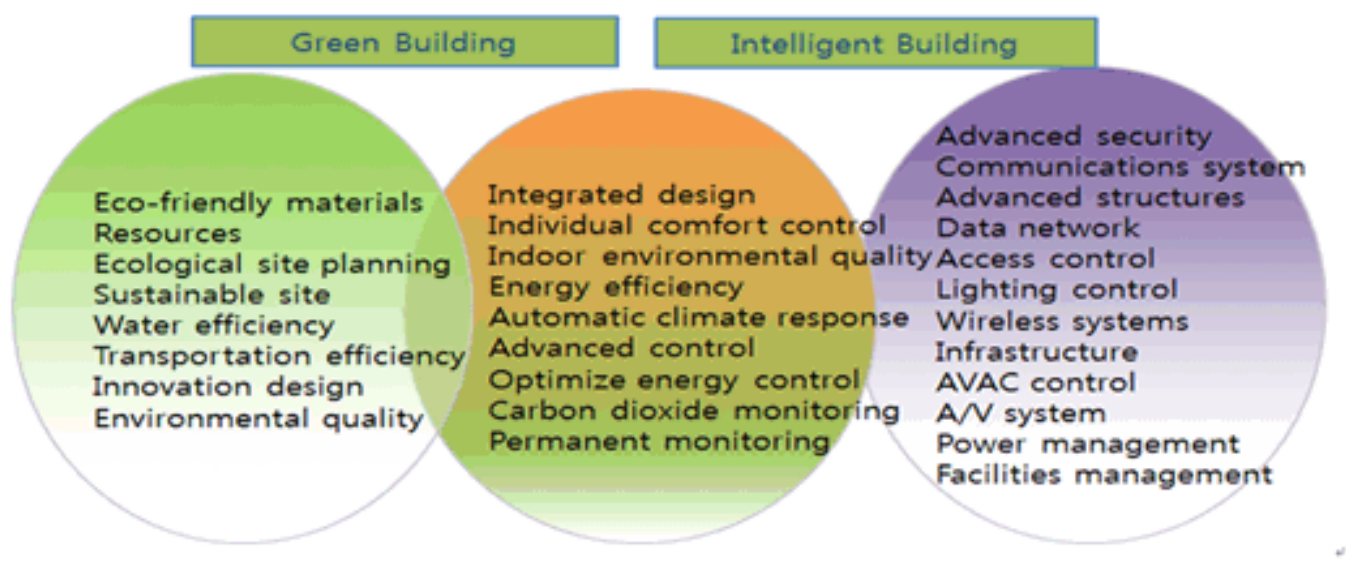

Figure 11. Green building design and intelligent building design (LEED) 


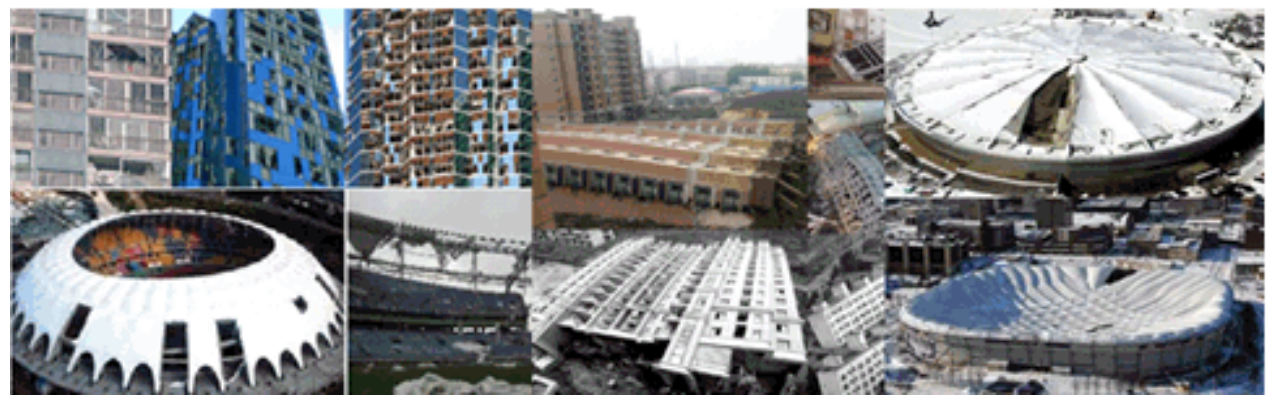

Figure 12. Disasters by typhoon, earthquake, and snow

\section{Nature-inspired Architecture}

\subsection{Hexagonal Design Inspired by Nature}

The honeycombs have an array of a perfectly hexagonal cross-section with a precise thickness and equal angles of 120 degree between them. The hexagonal cells are inclined to prevent the viscous honey from going out, and the entire comb is aligned to the direction of Earth's magnetic field. The hexagonal cells make the least total area of wall compared with triangle or square sections. The layer of soap bubbles becomes the combination of irregular hexagonal shapes. Nature is more good boundaries about the condition of economy. The surface tension of bubbles of soap films pulls the liquid surface to create it as small area as possible. The combination of typical bubbles has the polyhedral cells of different shapes and a little different curve. A slightly more economical structure was discovered the combination of a repeating group of different cell shapes for given boundary conditions. This bubble pattern was designed as the inspiration for the structural system of the 2008 Olympic swimming pool in Beijing. The compound eye of fly also can find the hexagonal packing as a bubble raft. The hexagonal patterns can find in radiolarian, the skin pattern of giraffe and the back pattern of turtle.

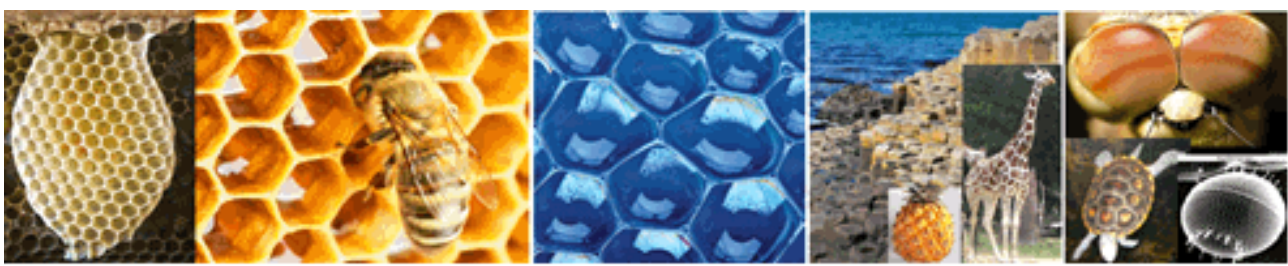

Figure 13. Hexagonal shapes in nature

Eden project for a botanical garden is designed the huge domes of the hexagonal steel frames and geodesic spherical network. The cladding system of ETFE foil cushion is a very lightweight system in constraint to glass. The ETFE film allows UV light to pass into a dome and also provides best insulation. The weight and amount of the steel was minimized by the optimum design, the cladding is transparent for the sunlight. The interior dome space and the bubble-shaped appearance are attractive with a high technical level for the architectural design and structural system. The surface has self-cleaning function so that the dirt on the outer-surface is washed down by the rain. The hexagonal-shaped cushions are attached on an aluminum frame, the pressure inside the cushion is about $300 \mathrm{~Pa}$. In the design of the high wind suction the outer surface was strengthened by using two layers of foil.

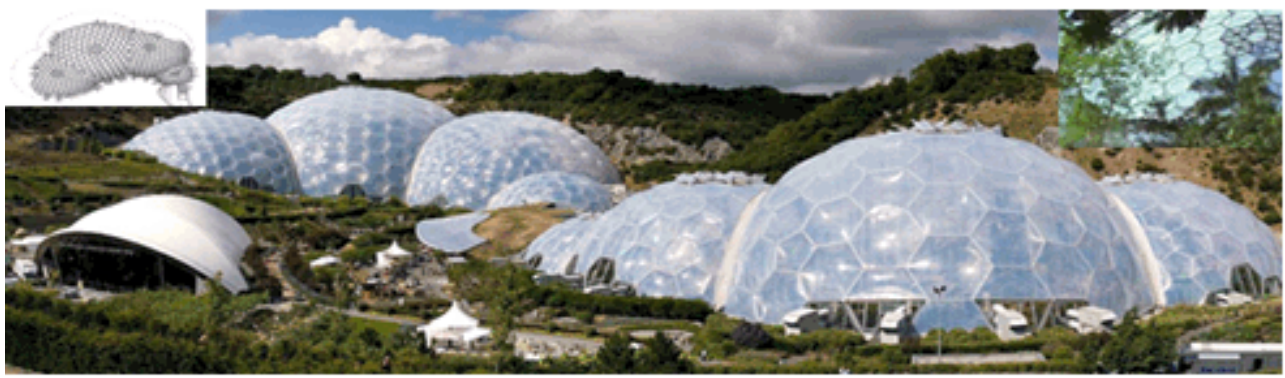

Source: http://www.studioseverini.eu/res/DocumentiPDF/eden_project_english.pdf

Figure 14. Eden project in the south-western tip of England 
The Beijing National Swimming Center was designed to act as the function of greenhouse, and remaining as a dramatic and exciting sporting venue with the innovative design of high technology biomimicry. The ETFE cushions allow the high levels of natural daylight into the building. The structural design was based on the most effective arrangement of organic cells and the natural formation of soap bubbles. The iterative procedure of structural optimization was carried out the finding of optimized size of steel members that satisfied all design constraints and resulting in the minimum self-weight. The arrangement pattern of roof has seven different pattern of bubbles and the wall has the combination of 15 repeated bubble patterns. The ETFE is a tough and durable plastic material that transmits more UV light than glass, and can clean thoroughly itself by natural rain. All pillows are permanently inflated by a pump for the internal pressure with $0.2 \mathrm{~mm}$ film thickness. The ETFE cladding allows more heat penetration than traditional glass, and resulting in a $30 \%$ decrease in energy costs. The flame does not spread when a fire occurs. The tensile strength is very good and the strain is very large, so it does not tear easily. Eco-friendly ETFE materials have a long service life with $100 \%$ recyclable.

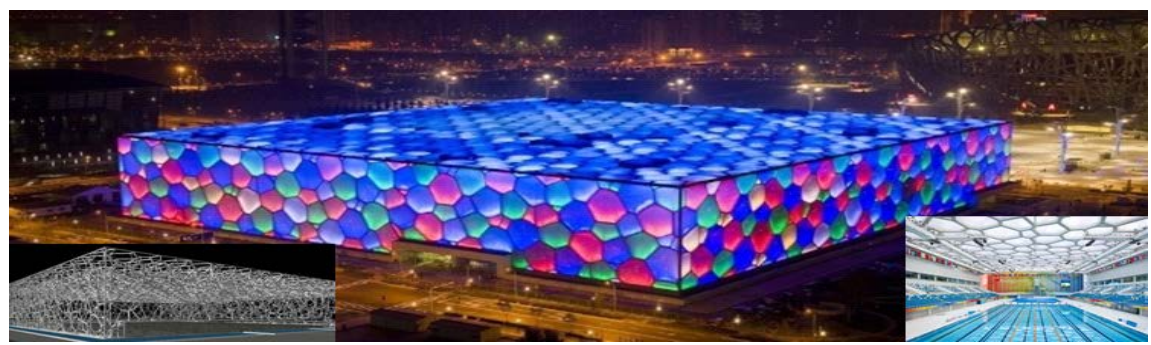

Source: http://www.discoverbeijingtours.com/home/Tools/2012/0922/National-Aquatics-Center.html

Figure 15. Beijing National Swimming Center

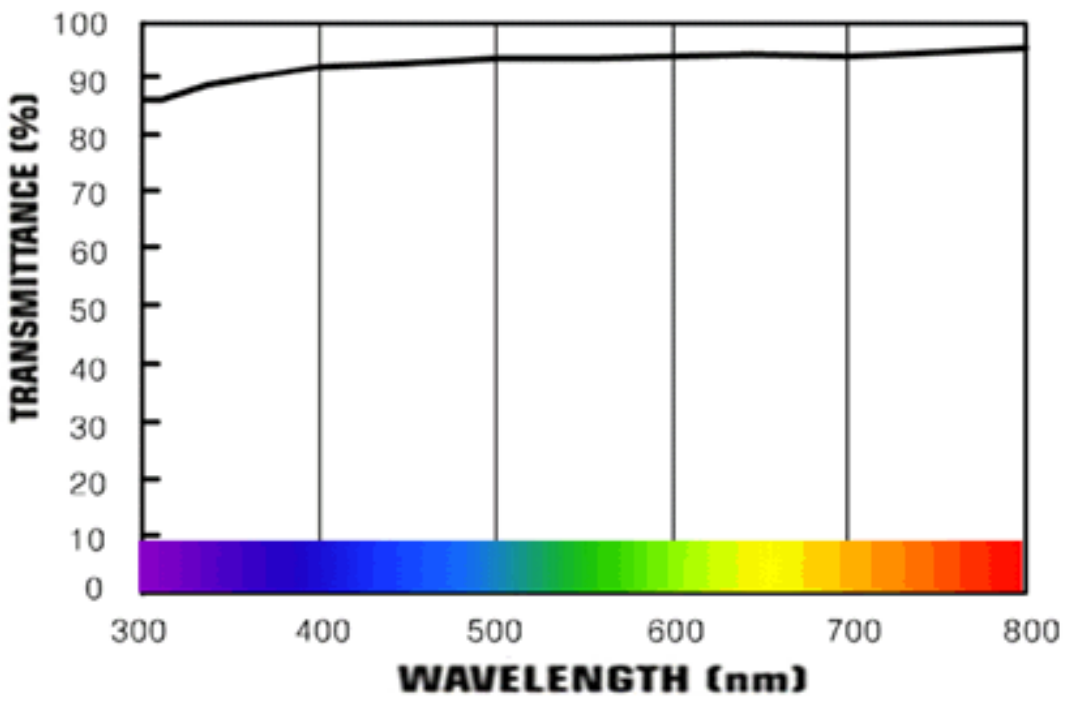

Figure 16. Light transmittance of ETFE Film
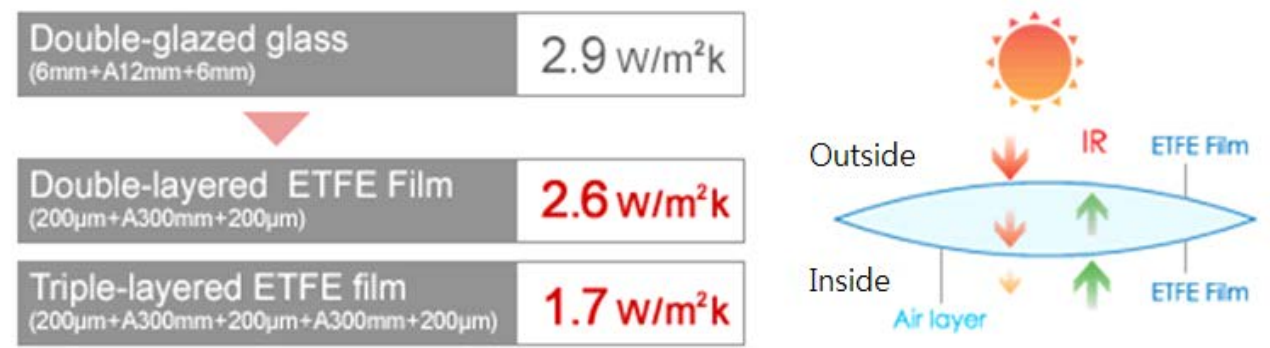

Source: https://www.makmax.com/business/etfe thermal.html.

ETFE film insulation properties are as effective as glass.

Figure 17. Insulation properties of ETFE film 
Double-layered
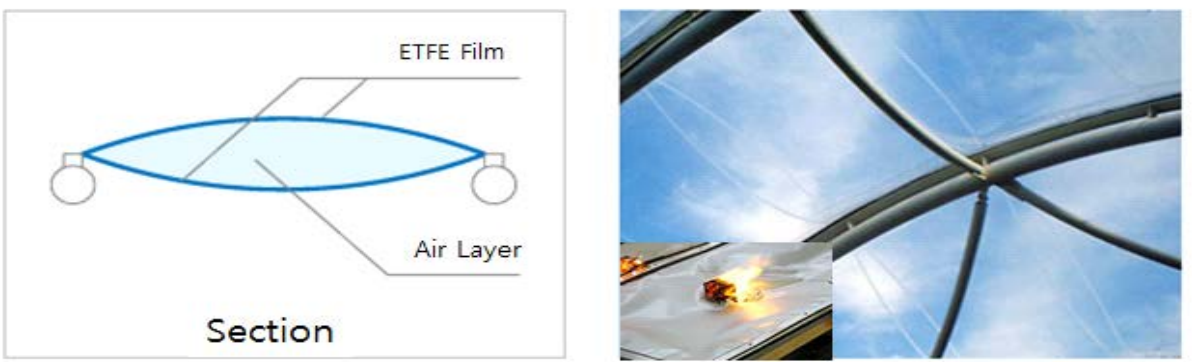

Triple-layered
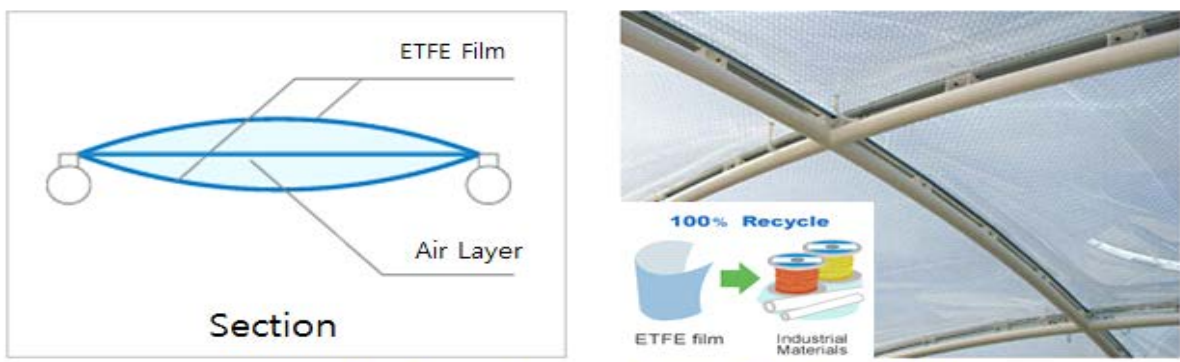

Source: https://unww.makmax.com/business/etfe thermal.htm!

Figure 18. Double-layered and triple-layered cushion

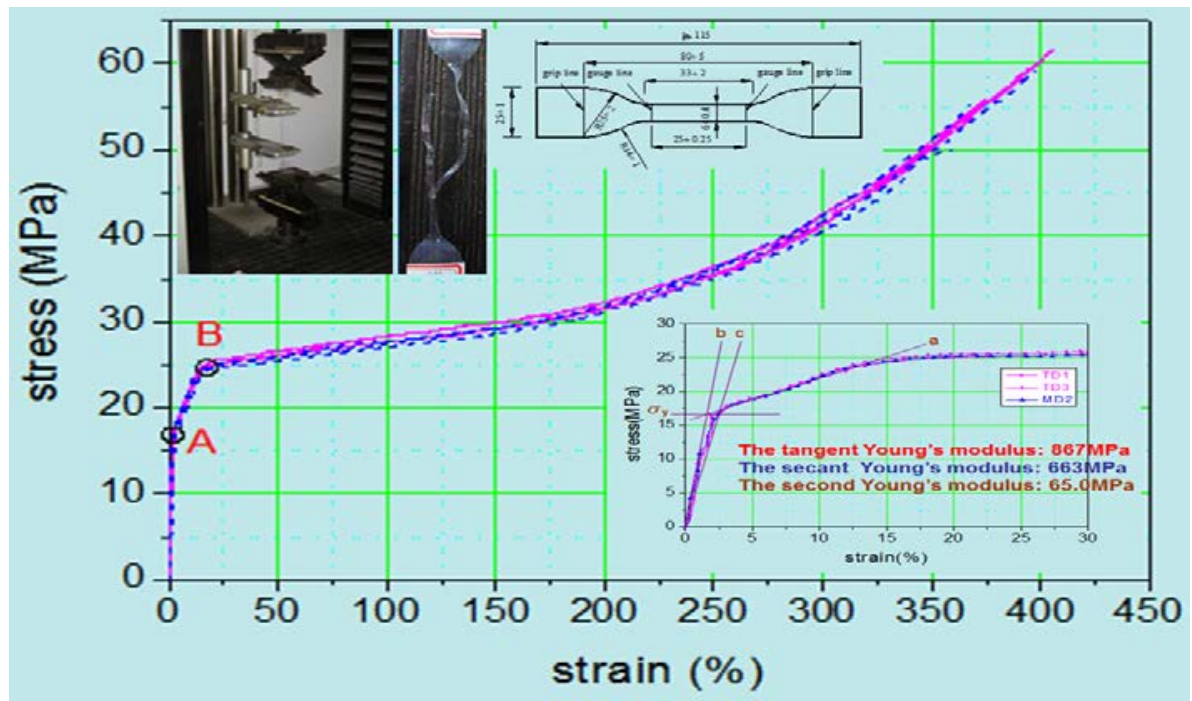

Figure 19. Stress strain relationship of ETFE film

\subsection{Cable Structures Inspired by Spider Web}

The spider seems able to vary the natural behavior in order to construct an optimal network structure according to the environmental conditions. The spider web is one of the resulting of complex animal architecture. The construction rule of spider provides a useful tool to explore behavioral strategies for the construction method of typical web. The spider make to tighten the first strand, then walk along it and strengthens it with a second thread. This process is repeated until the thread is strong enough to support the web, and the spider continues to make an overall network.

Natural spider webs have an analogical structure of a radial cable network, even though spider nets have no any rigidity. The network is applied to the system of cable structures for a large span space and a lightweight roof. The cable truss roof system has that the upper and lower cables are connected by bracing cables to resist the up and down load of the roof. The cable roof system is consists of outer compression ring, a center hub post, and continuous radial truss cables. The outer circular ring acting compression forces is in equilibrium with the tensile forces of inner radial cables. The upper ridge cables and the lower valley cables with a large prestress are connected to each other by a bracing cable to ensure structural stability and rigidity. The ridge cables and the valley cables are resiliently prestressed and the curvature in the reverse 
direction cables is maintained the stable shape. In the cable truss systems, various cables have strong mechanical properties and high tensile strength, enabling the design of large space lightweight roof of $100 \sim 300 \mathrm{~m}$. The cables have a very strong tensile forces, but have very flexible and no the bending resistance. The retractable roof system opens and closes the part of roof to maintain the required optimum environment of the stadium to overcome the outside extreme climate, and it is possible to play in cold weather and hot weather, and it creates the good environment conditions of a healthy exercise for athletes. The cable roof system can reduce dramatically the roof self-weight compare to the steel frame roof.

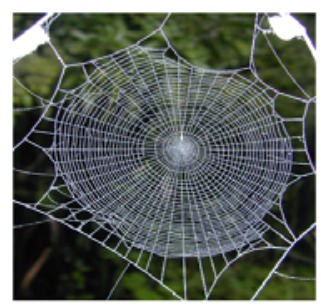

Natural spider webs

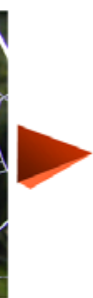

ial cable network inspired by spider web

The Munich stadium complex for the 1972 Summer Olympics is a perfect arena of how site and structure can harmony together. The design of cable roofs for the arena of first membrane structures in the world is to unify the earth. The roof shape was inspired by Alps mountain. Until now, the system is very famous as ultra-light space structures, and the design concept and technology are proud of German's architecture.

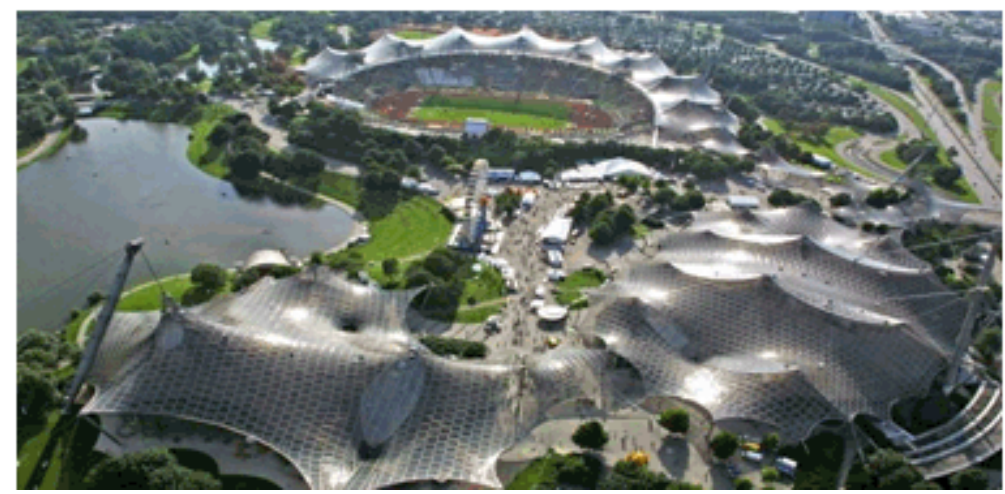

Source: http://wlrn.org/post/archtitectures-top-prize-awarded-miami-beach-friday

Figure 21. Munich stadium complex

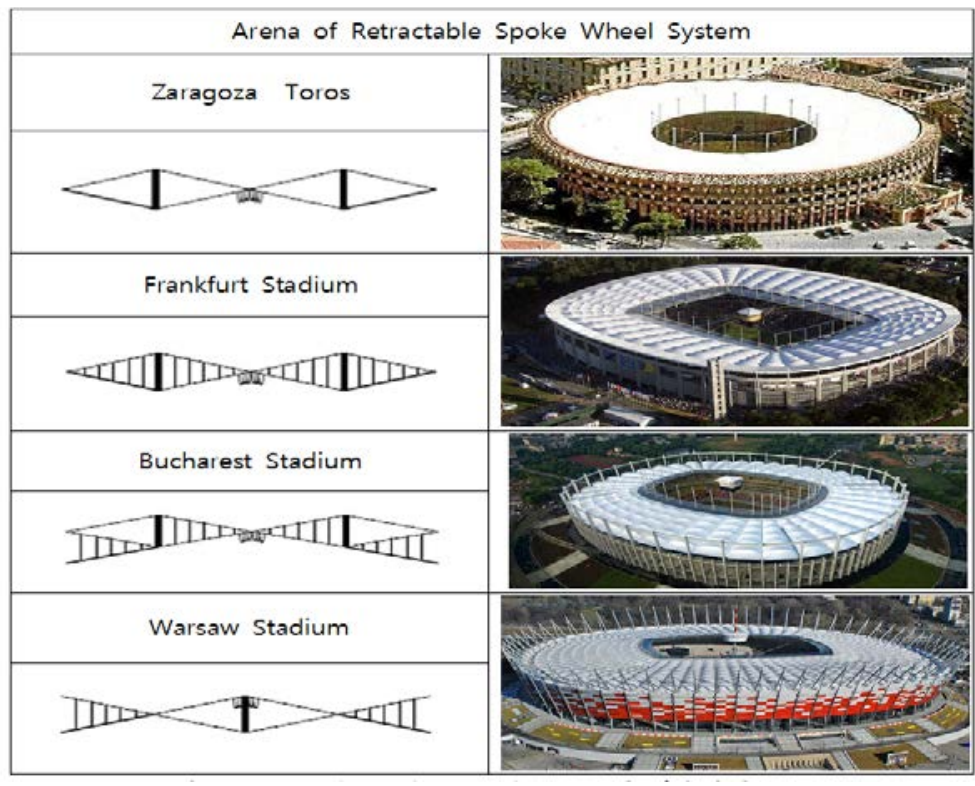

Figure 22. Arena of a retractable cable roof system 
Cable truss roofs mainly use a spoke wheel-like system and a radial roof system to build a lightweight large span roof. A large span cable truss roof is a system that combines two spoke wheel systems to adjust the slope of the roof by adjusting the height of the roof post and the outer ring. The outer part of roof is designed a fixed membrane roof, the inner part of roof have the retractable system that can be opened and closed. In the method of opening and closing of the entire roof, it is possible to simultaneously open and close the central part and the outside part. In typhoons and heavy snow, it can be closed or opened to prevent damages to the membrane material and structural members. It is better to close the roof during typhoon, and it is better to keep the opening state of roof during snowfall. A retractable roof system is important to consider moving states of retractable roof during opening and closing. Each state changes with load conditions. The safety level depends on the purpose and importance of the building that it is aiming at.

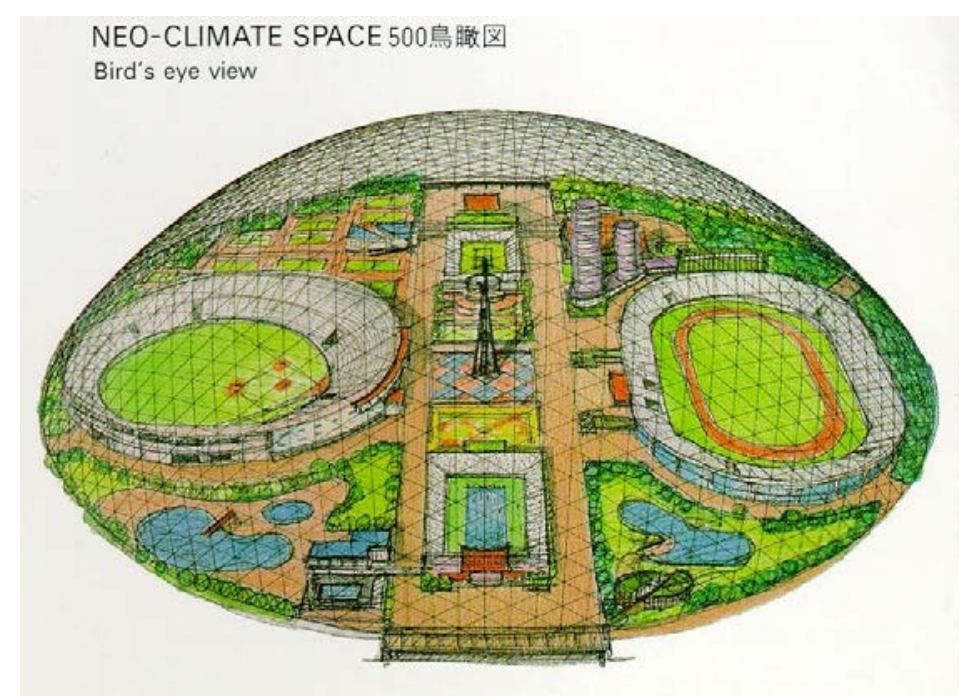

Figure 23. Plan of NEO-CLIMATE SPACE 500 (Japan)

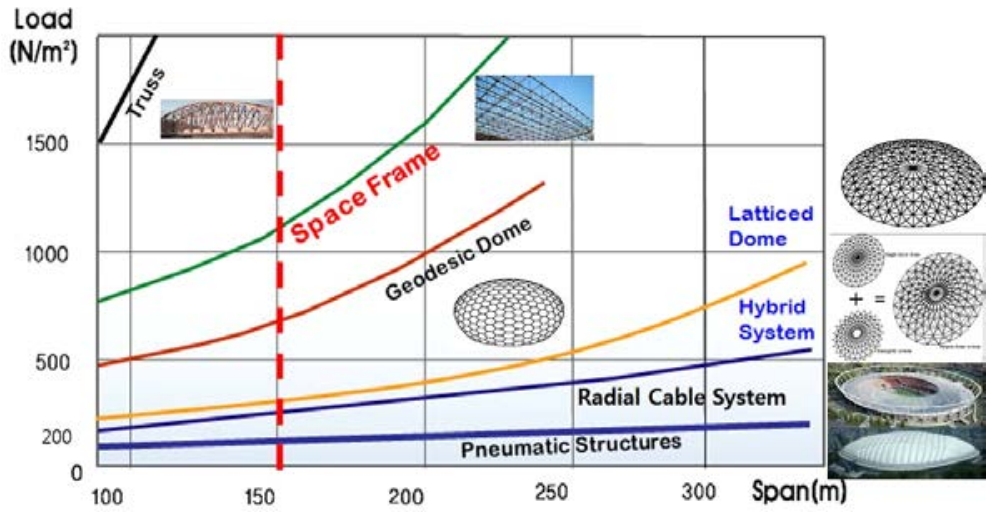

Figure 24. Comparison of a roof self-weight

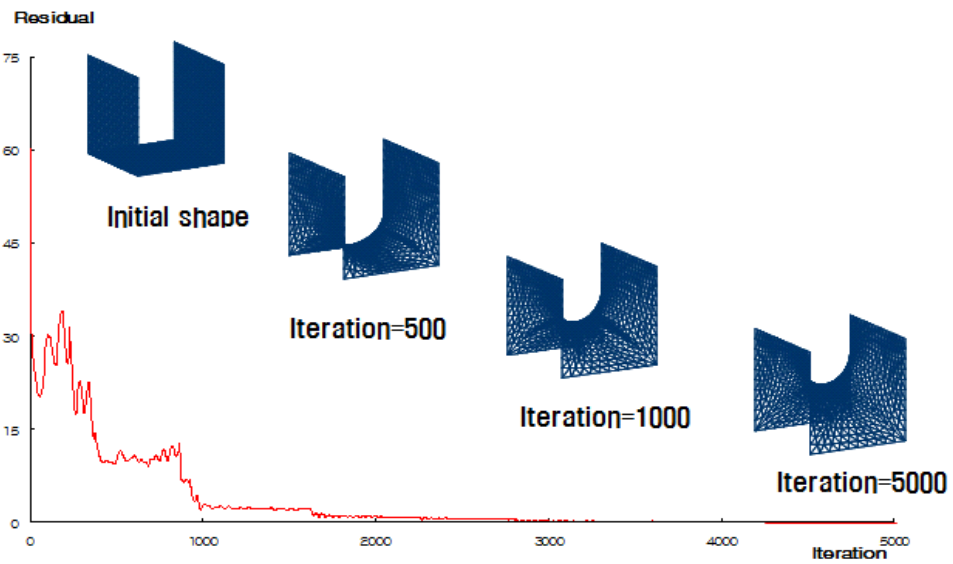

Figure 25. Form finding of a membrane roof 
The designer should be aware of the desired safety level according to the social and economics. The method of considering the safety in the opening and closing method is different from the opening and closing state when it moves. The conditions of roof should be clarified taking into consideration whether the roof is to be opened, closed or half-opened. It is normally a good for in a closed state at the time of storm and strong wind in the retractable roof and should be closed when the wind speed exceeds the specified wind speed. Variation of wind speed during roof opening and closing should be considered. The folding-type roofs are designed to the membrane in order to form an appropriate curved surface. The movement method of the opening and closing part can be planned a retractable system for horizontal sliding, horizontal folding or rotational movement. The moveable roof should be considered to structural design for the lateral shaking during the movement, and the upward and downward shaking motion when the roof is running.

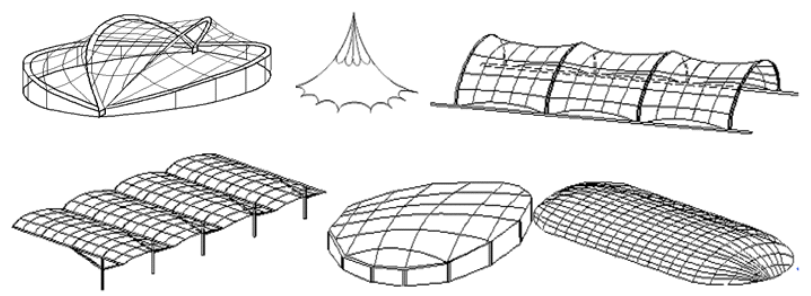

Figure 26. Design of various cable structures

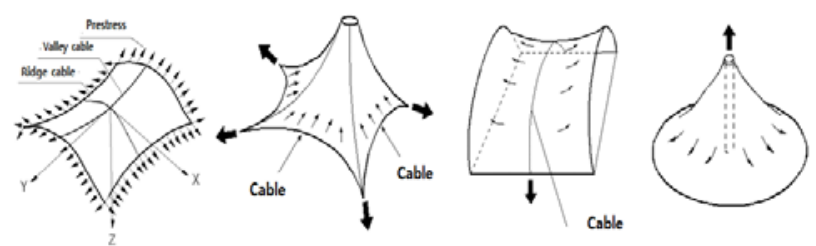

Figure 27. Prestress method of fabric surface

\subsection{Building Design Inspired by Flower}

Lotus flowers are known to be associated with purity, spiritual awakening, and sincerity for all Buddhist saints. Lotus leaves and flowers have wax-like surface of each epidermal cell. As a result, raindrops carry dust particles and keep the surface clean. The properties of cleaning surfaces in plant leaves have opened the possibility of manufacturing various ultra-hydrophobic products, such as paints, glass, and windows. The large-scale imitative Lotus Conference center is the government center in the Wujin district, which resembles the pink lotus flower. The structure is described by a combination of sculpture, and a powerful sensuous and feminine biological form. The building becomes one of the most famous icons in the city. The design is a striking design inspired by the blooming of lotus flowers.

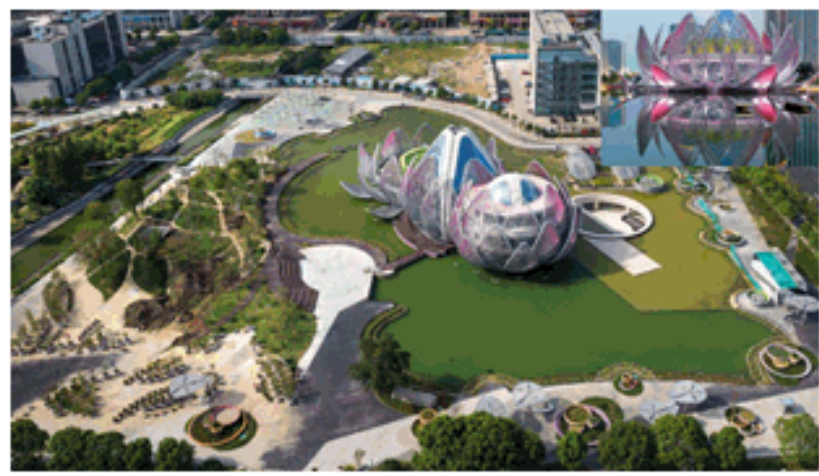

Source:

https://www.curbed.com/2014/3/7/10135008/chinas-latest-bizarre-buildi ng-is-a-giant-ethereal-lotus-flower

Figure 26. Wujin Lotus Conference Center in China

The Qizhong Forest Sports City Arena has eight sliding steel roofs that resemble the white magnolias of Shanghai, China. It has a foldable steel roof which is switched by the control of the indoor environment. The opening design of the roof signifies the blooming condition of a magnolia. It takes 8 minutes to fully open or close the roof. The stadium is designed to cope with the weather by acting like a blooming of flower that closes and opens its roof. Each of the eight movable petals moves and rotates at the same time over one fulcrum and three rails.

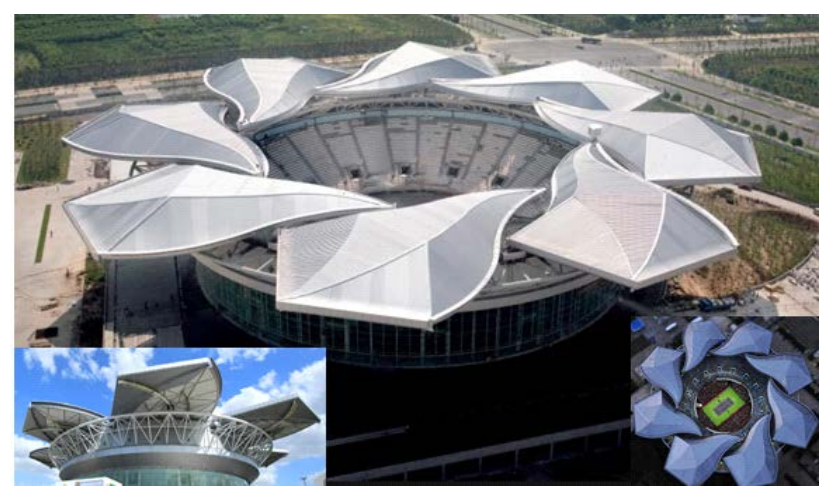

Source:

https://en.wikipedia.org/wiki/Qizhong_Forest_Sports_City_Arena

Figure 27. Qizhong Forest Sports City Arena

\subsection{Curved Structures Inspired by Seashell}

Seashells have been successfully playing a role in protecting inner part for hundreds of millions of years. Scientists and chemists are trying to replicate the structure of this material, and can be expected to be used as a stronger building or a bone substitute. When cracks are formed, the polymer of seashell has a structure that grows and strengthens. Natural composite materials are renowned for their mechanical characteristics of strength and toughness. The crossed lamellar microarchitecture of the seashell provides for channel cracking in the outer surface and uncracked structural features that bridge the crack surfaces, thereby significantly increasing the characteristics of fracture and toughness. 


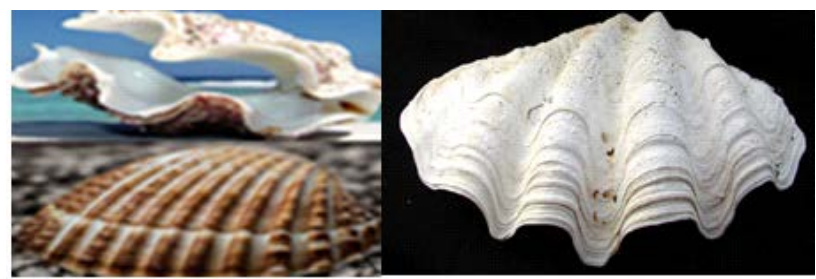

Figure 28. Seashells

In Valencia, Spain, the marine city around the sea has been beautifully made using concrete shell structures with the images of seashells. HP dual curvature was used to minimize the bending moment and create a shell structure with a thin curved surface that produces only in-plane compressive forces. In the 1960-70, it was a method of making large space structures using mainly concrete. The geometry of the concrete shell structure was consists of the intersection of hyperbolic paraboloids.

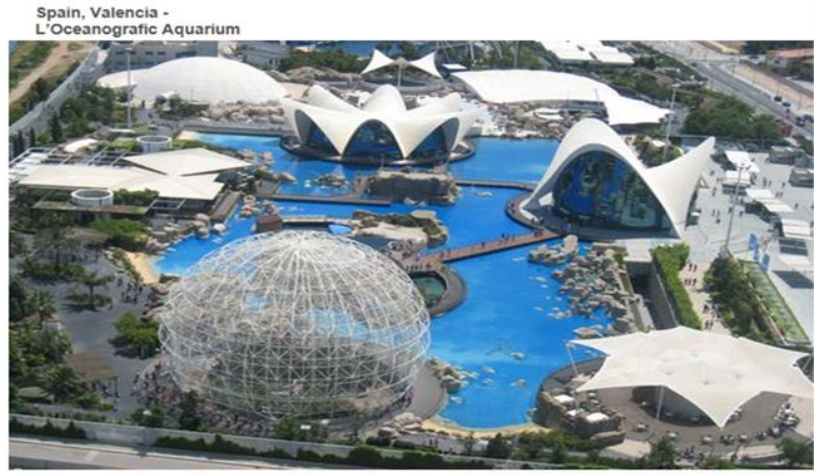

Source: https://umw.pinterest.co.kr/pin/196539971214679491/.

Figure 29. The marine city around the sea in Valencia

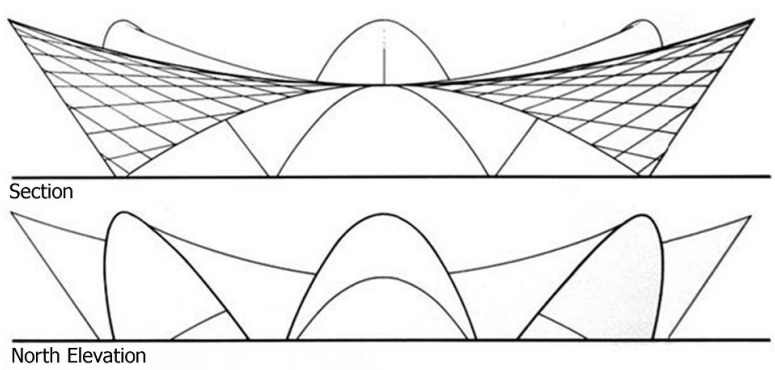

Figure 30. HP dual curvature of Aquarium Oceangrapic

Felix Candela (1910-1997) started experimenting with the umbrella structures in 1952. The shell geometry was created by joining four straight edged hyper whose sides rose upwards. Umbrella structure is a type of inverted pendulum. Precisely, it is a cantilevered structure. The basic structural scheme of an umbrella consists of a foundation, only one column with an embedded pipe to catch the rain water. Candela used to create dramatic roofs of large spaces, such as the roof for the Church of the Miraculous Medal, built in 1955 in Mexico. The church is a remarkable building. It is somewhat reminiscent of the Gaudi's forms. The structure is a combination of super-warped hyper surfaces with a thickness of $4 \mathrm{~cm}$ or less. The Cuernavaca Chapel shell is self-supporting with the span of $30 \mathrm{~m}$ and dramatic curvature. The open end of the chapel rise to a height of 24 meters and has a visible thickness of $4 \mathrm{~cm}$ that represents the frontiers of the form. The underwater restaurant and a large oceanographic park in Spain were the Candela's final projects. The shell is only $6 \mathrm{~cm}$ thick that gradually increases up to $22.5 \mathrm{~cm}$ at the intersection of the ribs. The geometry of the concrete shell structure for the entrance building was consists of the intersection of three hyperbolic paraboloids.
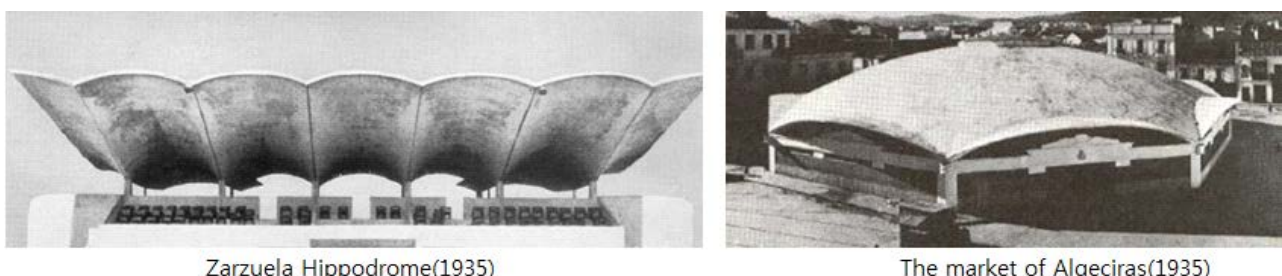

Figure 31. The concrete shell structures designed by Torroja
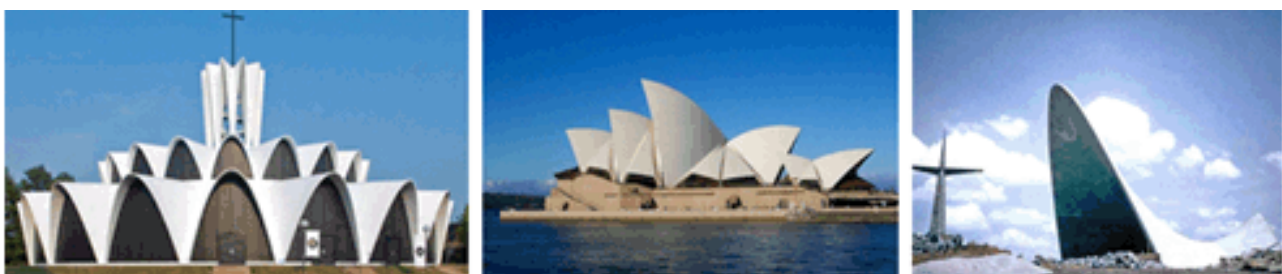

Figure 32. The concrete shell structures 
Pier Luigi Nervi (1891-1979), one of the greatest and inventive structural engineers of the 20th century, developed new shell structures inspired from Roman and Renaissance dome architecture applying rib and vault system to improve strength and eliminate columns for large space. Nervi began to design concrete shell structures of several airplane hangars in 1935. Orbetello and Torre del Lago improved the design by using a lighter roof, precast ribs, and a modular construction method in 1939. During the 1940s he developed new shells for reinforced concrete which helped in the rebuilding of many buildings and factories throughout Western Europe. Some of his most important and iconic works were realized in Italy and Europe: the Exhibition Halls and the Palazzo del Lavoro in Turin, the stadium in Florence and the Sport Palaces for the Olympic Games of 1960 in Rome. He combined shell geometry and prefabrication to innovate construction methods.
Eduardo Torroja (1899-1961) was characterized by the use of continuous shell, especially prestressed reinforced concrete. He said the best structure is the one that is held by its shape and not by the hidden resistance of its material. Frank Lloyd Wright said about him Torroja has expressed the principles of organic construction better than any other engineer.

The perfect surface can find a soap film in which the surface tensions are the same in all directions. This forms a minimal surface and is a good starting point for finding a surface tensioned structure. Frei Otto was used to stretch fabric models for a form finding modelling. The inverse hanging chain models is the form by the self-weight loads would produce only compression forces. Recently, instead of a roof system using concrete, steel pipes and cables has been developed. The self-weight of the new roof systems reduced dramatically.

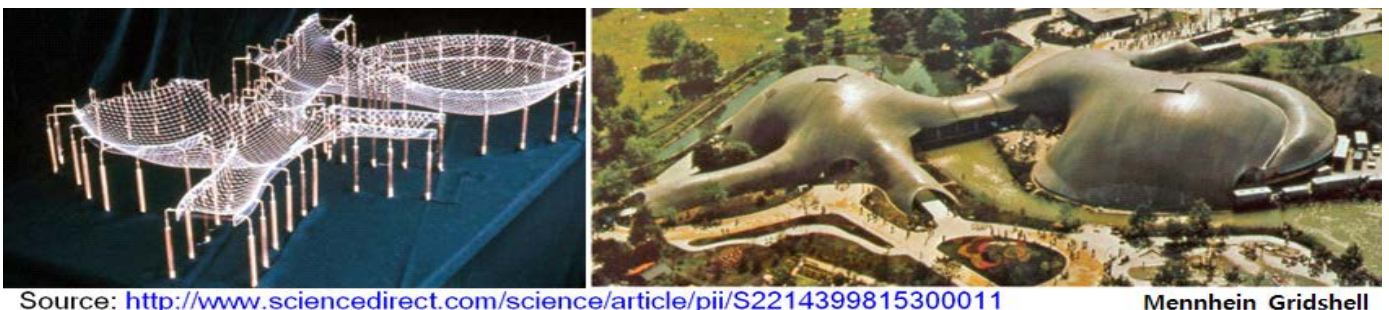

Figure 33. Mennhein Gridshell
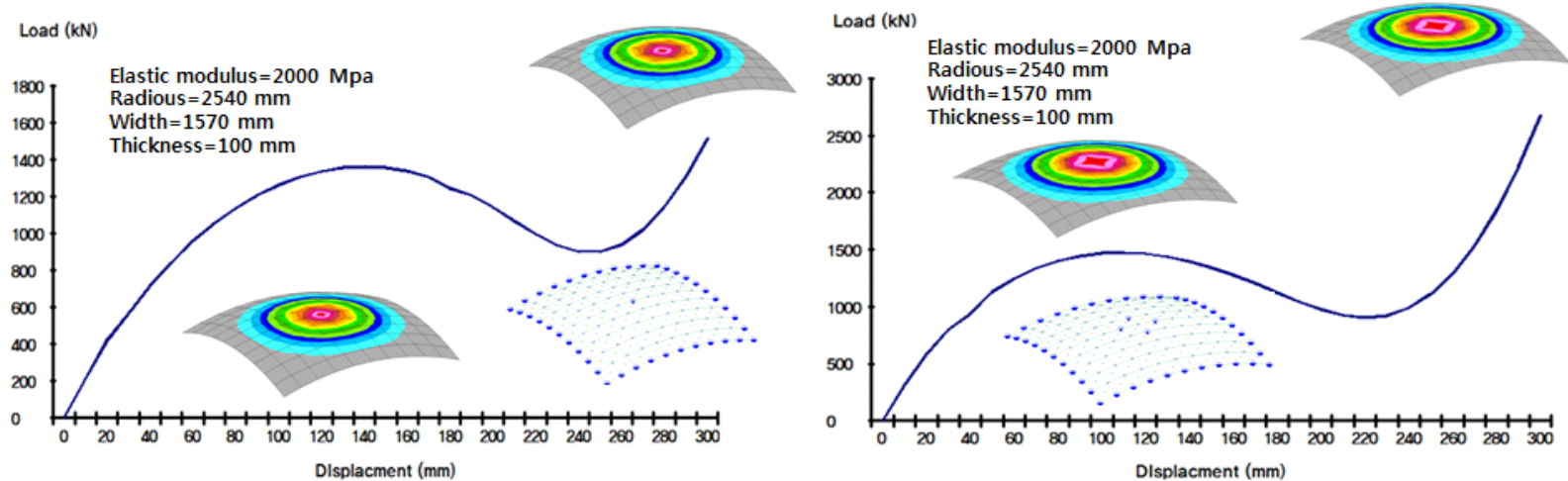

Figure 34. Snap through behavior of shells

The entire load history for a typical nonlinear analysis may be divided into the step event. An event may have increment load steps. Step size (load increments or time increments) may be determined automatically or user definition. In each increment analysis, it is defines parameters for step (or time increment) size, number of steps, equilibrium checks, tolerances for convergence, iterative procedure and other control parameters. The snap-through and snap-back buckling phenomena pose some of the most difficult problems in nonlinear structural analysis. The arc length automatic stepping can be applied to overcome the problems of stiffness singularity and post-buckling. The general goal of arc length procedure is the control of iteration in the numerical solution of complex nonlinear problems. The main idea of this method is based on the concept of constraining the length of the incremental displacement. The incremental displacement length for each iteration is constrained by the length of the previous iteration. Correspondingly, the load is adjusted in order to satisfy the global equilibrium requirement of the system. 


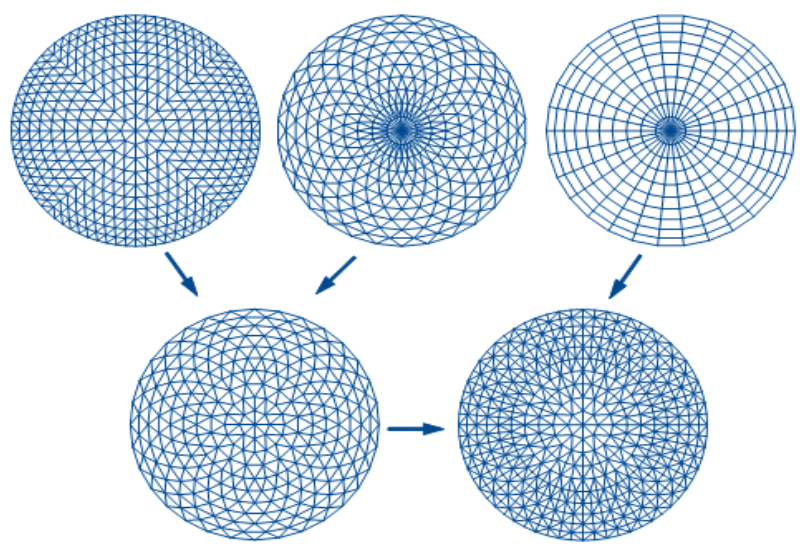

Figure 35. Creation of mero dome by the assembly of members

A space dome is arranged in an array of single, double, or multiple layers of intersecting members. A single layer space dome is the form of a braced dome or latticed shell. A space dome is assumed as hinged joints and therefore has no internal moments. The choice between space frame and space truss is mainly determined by the joint-connection detailing and the overall geometry is no different for both. However, in engineering practice, there are no absolutely rigid or hinged joints. A double layer flat surface space frame is usually analyzed as hinged connections, while a single layer curved surface space frame may be analyzed either as hinged or rigid connections. The space frame will be used to refer to both space frames and space trusses. In the analysis of structural behavior, it is important to analyze the member buckling, the node buckling and the stability of entire structure for the snap through or back behavior. The search for new structural systems has always been the main objective research of architects and engineers. With the industrialization and development of the modern world, there is a demand for efficient and adaptable spatial structures. Recently space structures are new forms, owing to their wide diversity and flexibility. A growing interest in space frame structures has been witnessed worldwide over the last half century. With the advent of new building techniques and construction materials, space frames frequently provide the right answer and satisfy the requirements for lightness, economy, and speedy construction.
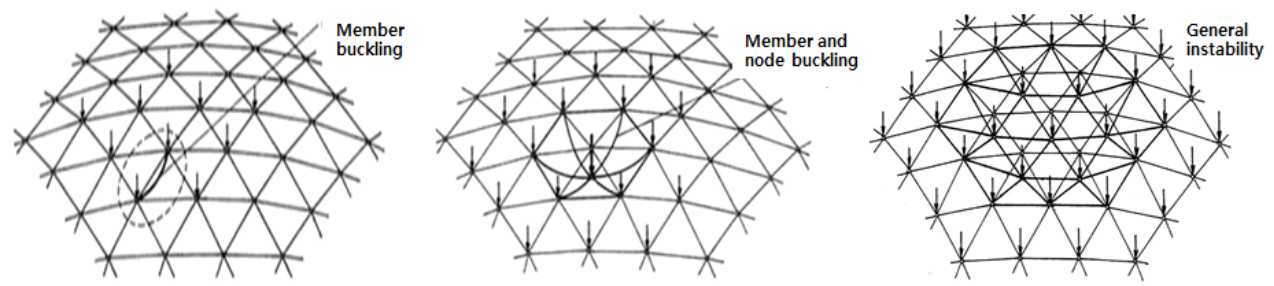

Figure 36. Bucking and instability of domes

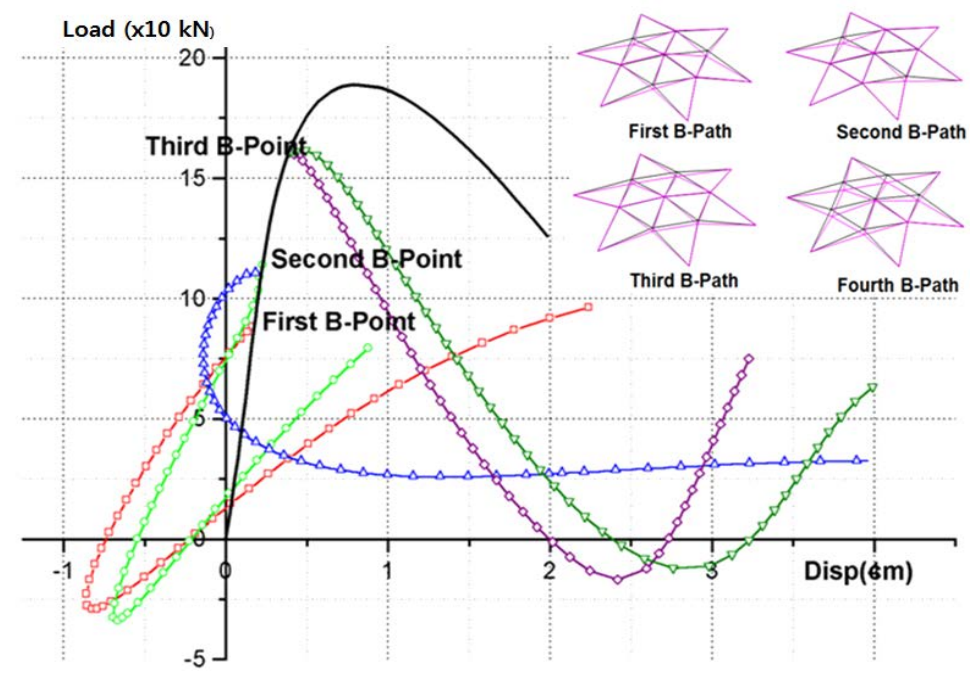

Figure 37. Snap through buckling of a star dome 


\subsection{Tensegrity Systems Inspired by Nature}

Tensegrity system can find the system of muscles, bones, the tendon of animal, the molecular structure of spider fiber, cells in biological material, collagen, DNA, and carbon nanotube. The elbow, shoulder and foot can be thought of as a tensegrity joint. A rabbit's legs show the time profile of the forces in each tension during a walk. The molecular of spider web is the strongest fiber in nature. Tensegrity systems are the structures of a special nature and their industrial use has not yet been fully developed. The systems are geometrically and mechanically complex. Researchers are encouraging the designing of tensegrity systems open up new prospects for new structural systems. Scientists from various fields of study are beginning to realize the mechanical forces are just as important as biochemical signaling in shaping proper cell development, function, and pathologic processes. The recognition is to understand the hierarchical organization of biological organisms. It is defined tensegrity architecture and biotensegrity.

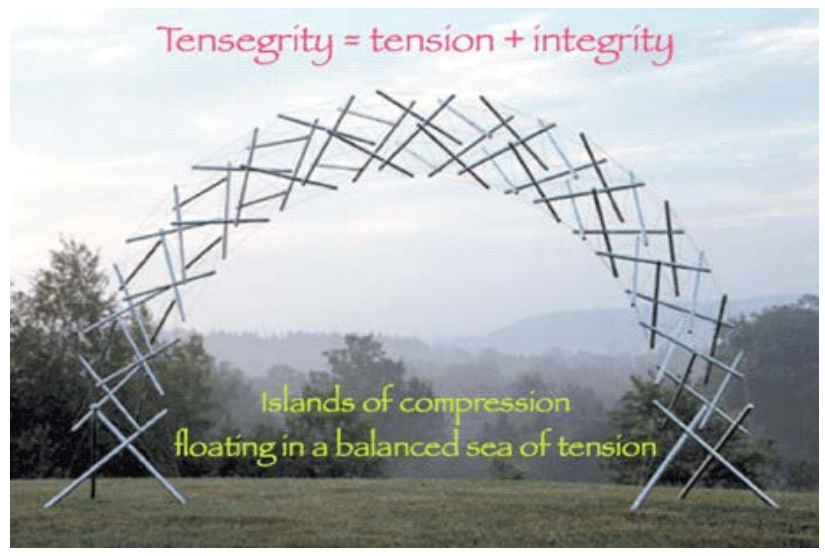

Figure 38. Tensegrity=tension + integrity

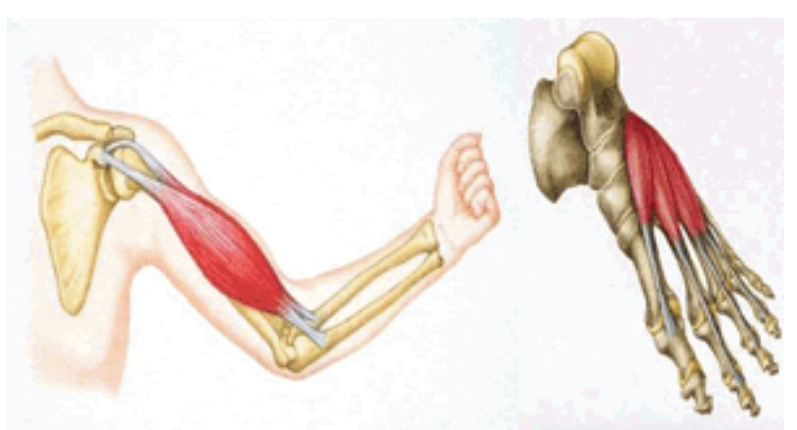

Figure 39. The elbow and foot can be thought as a class of tensegrity joint

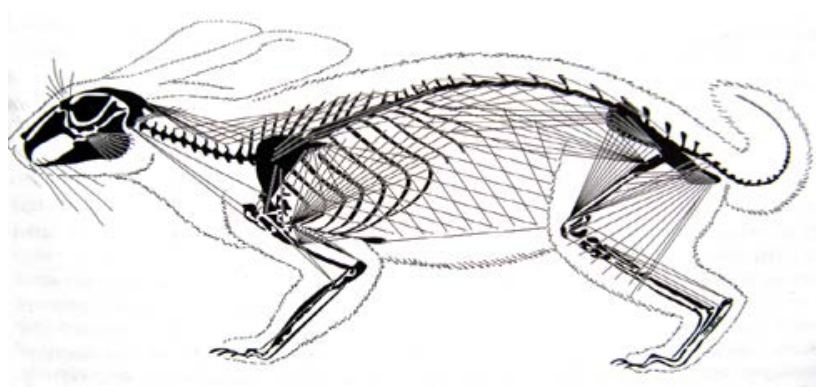

Figure 40. A rabbit can be thought as biotensegrity system

According to the tensegrity principle, structures are stabilized by continuous tension with discontinuous compression. The manmade structures are stabilized by gravitation compression. Tensegrity would maintain their shape and equilibriums in absence of gravity. Prestressed tensegrity structures are formed from the combinations of discontinues compression-resistant members and continuous tension members. Geodesic tensegrity structures are stabilized through force tri-angulation, and the individual members are capable of alternating between generating tension under prestress or resisting compression. Tensegrity structures allows extremely efficient, lightweight, and strong. A number of key elements of tensegrity systems are important in applications to biological organisms, and intrinsically self-stabilized by prestress and triangulation. The cell is to respond to change external forces by transmitting the forces throughout the cell with tensegrity architectural principles. The human body can represent biotensegrity at the molecular, cellular, tissue, and organ system. The focal adhesion biotensegrity model represents the vital link between the extracellular matrix and the skeletal system.

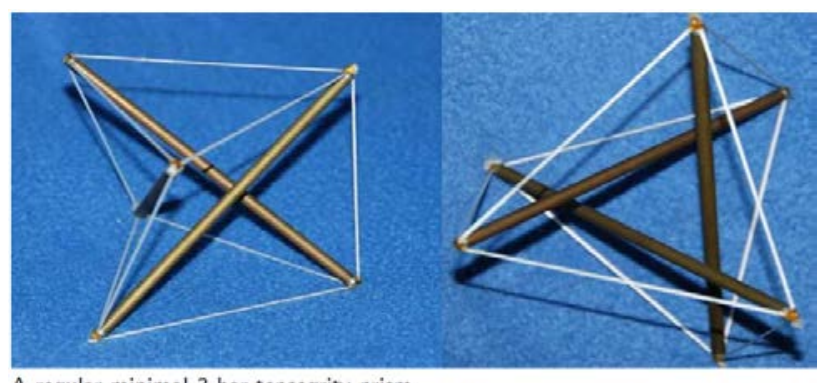

A regular minimal 3-bar tensegrity prism

regular = tops and bottoms have same vertical centerline and are parallel. minimal $=$ stabilized with smallest number of strings possible

Figure 41. 3-bar tensegrity systems

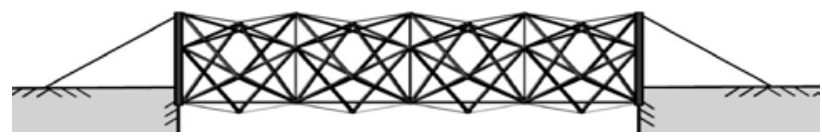

Figure 42. A tensegrity bridge 

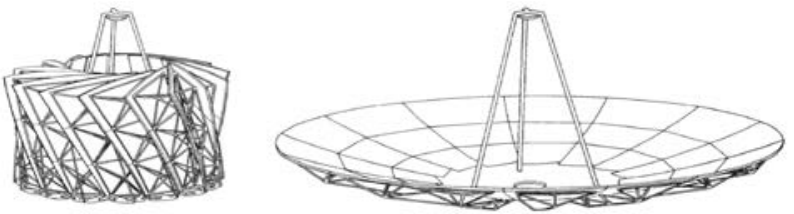

Figure 43. A deployable tensegrity system
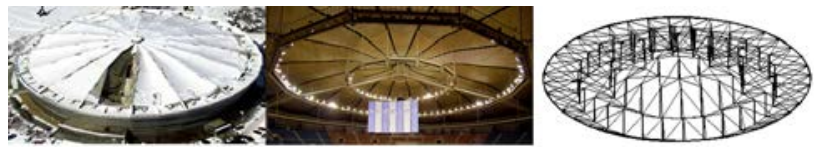

Figure 44. Seoul Olympic Gymnasium (the first tensegrity roof system, 1988)

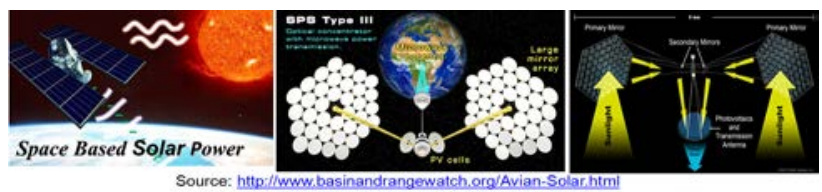

Figure 45. Space solar power structures designed by deployable tensegrity system

\subsection{Examples of Modern Architecture Inspired by Nature}

The vast majority of development in China's new cities takes the form of residential housing. It is possible to build high-density, economically viable housing that is also architecturally innovative. This development is located on the coastal city of Beihai, south of China, narrow oceanfront site. The fundamental geometry of the scheme was producing an undulating building typology, and resulting in a form of a hill. The geometry of the architecture maximizes potential views for the residents; the continuous platform along the roof becomes the public spaces. Each opening in the building allows the sea breezes to pass through and creating ocean views from the interior. Aiming for a high-density solution and a new landmark for the city, Fake Hills provides a heightened experience of the coastline and an opportunity for unhindered interaction with the city and the vast nature ahead it faces.

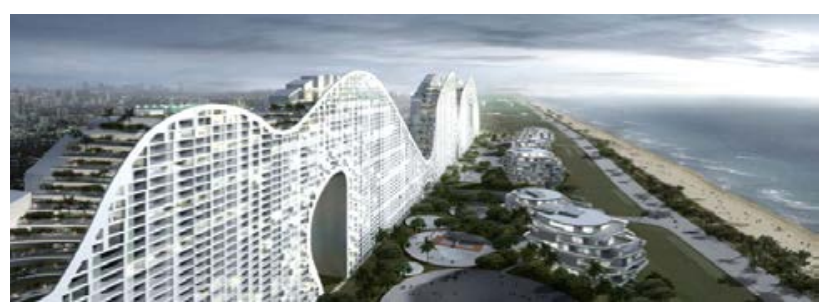

Source: http://www.itsliquid.com/mad-architects.html

Figure 46. Fake Hill designed by MAD architect (China)

Toyo Ito drew inspiration from the formation of rocks, caves and the transience of water for his design. The theater takes the cave-like form to create the continuous surface. The shape was designed by acoustic optimization rooted the way sound carried through space. NTT has created a theater for extraordinary and wonderful arts, and has made the recognition of art in a part of everyday life. It provides the richness and joyfulness of urban life through festivals, performances, and cultural events centering on the theater as a landmark of the city. The NTT is provide to the new vision of creating a theatre for the extraordinary and awesome arts, embrace the diversity of artistic programs, including music, dance, opera, drama, music theatre, and digital performing arts. By hosting an annual arts festival, providing presentation platforms, developing a network of local and international artist communities. Designed by Pritzker winner and UIA 2017 gold medalist, Toyo Ito, the NTT is supported solely by curved walls with no pillars, become one of the most awesome theaters in the world that inspire artists, audience, and all neighborhoods. In Japan, the experience of the tsunami recognized that humans cannot overcome nature with technology. Modern Japanese cities have no traditional houses and are filled with high-rise apartments and offices. The higher the building is constructed, the more separated it is from nature. For nature-friendly architecture, Ito designed a library with the concept of reading books under the tree. Toyo Ito was born in Seoul. After graduating from the University of Tokyo, he worked at Kiyonori Kikutake Architects and Associates. He established his own office under the name Urban Robot, in 1971. Ito has completed many notable projects, including the widely published Sendai Mediatheque (2000), Tower of Winds in Yokohama (1986), Tama Art University Library (2007), and Toyo Ito Museum of Architecture (2011). Toyo Ito's many awards received for architecture include the Golden Lion for Lifetime Achievement, at the 2002 Venice Architecture Biennial, and the Golden Lion for Best Pavilion, for the Japanese Pavilion at Venice in 2012. He received the Gold Medal in UIA2017 congress.

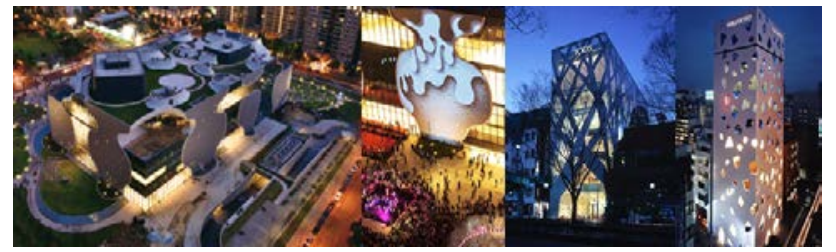

Source: http://www.toyo-ito.co.jp/WWW/index/index_en.html

Figure 47. Nature-friendly buildings designed by Toyo Ito

German architect Wolf Hilbertz, a German-born futurist architect, designed an artificial island. It is a system that supplies the electricity by utilizing the sun and wind energy by minimizing the use of materials by introducing the natural form by designing the vortex form of the sea. London City hall was designed as a swirl system inside the hall. The elliptical design minimizes the energy loss by reducing $25 \%$ the surface area of general buildings. In addition, the building inclined to the south with a 31 degree tilt wrapped in glass, minimizing the influx of sunlight in summer and maximizing the influx of sunlight in winter. City Hall planned to respond to the necessity for democracy by drawing the public in with its iconic building form. The building designed to set the standard for environmentally conscious systems, City Hall was a passive and active design to achieve sustainability. 

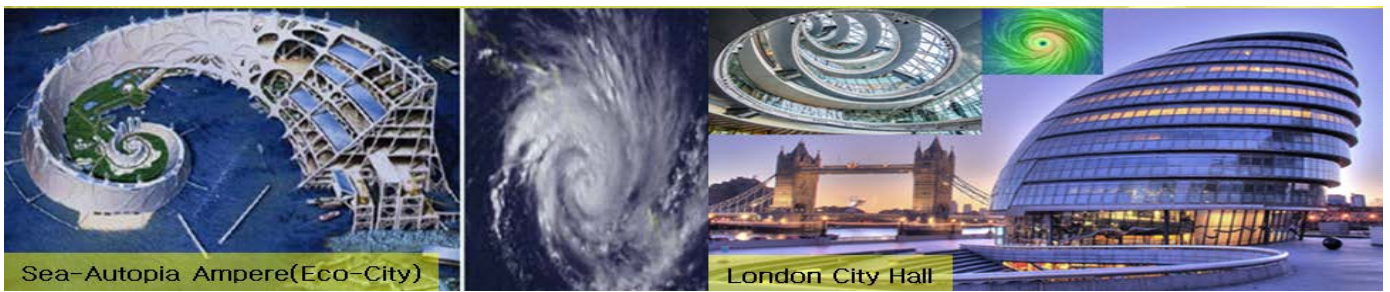

Source: http://www.rexresearch.com/hilbertzbiorock/hilbertz.html

Figure 48. Eco-friendly building inspired by spiral

The 2022 Qatar stadiums aim to employ cooling technology capable of reducing temperatures within the stadium by up to $20^{\circ} \mathrm{C}$, and the upper roof of the stadiums will be disassembled after the World Cup and donated to countries with less developed sports infrastructure. All of the five stadium projects launched have been designed by German architect Albert Speer \& Partners. The stadiums were inspired by nature-friendly design concepts.

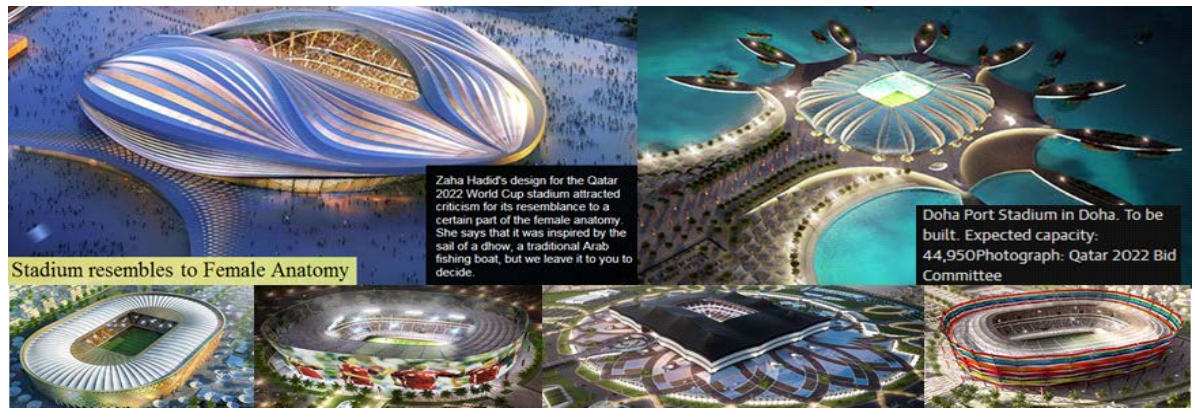

Source: https:/www.theguardian.com/football/gallery/2010/dec/02/world-cup-2022-qatar-stadiums-pictures

Figure 49. Q Qatar 2022 world cup stadium

The snowflake changes shape according to temperature and is optimized for air condition, humidity, air pressure, etc. Considering snow crystals, all planar forms are found to have star-like forms with six corners as a symmetrical form of a regular hexagon. The molecular structure of the snowflake can be considered as a building system. The snowflake results governed with the least-energy interactions with the environmental consideration of temperature, humidity, wind velocity and atmospheric pressure under which it is formed. The plan of Palmanova city in Italy was inspired by snowflake. Palmanova was planned to be a utopia inhabited by merchants, craftsmen, and farmers. The builders imposed geometrical harmony into its design that the beauty reinforces the wellness of a society.

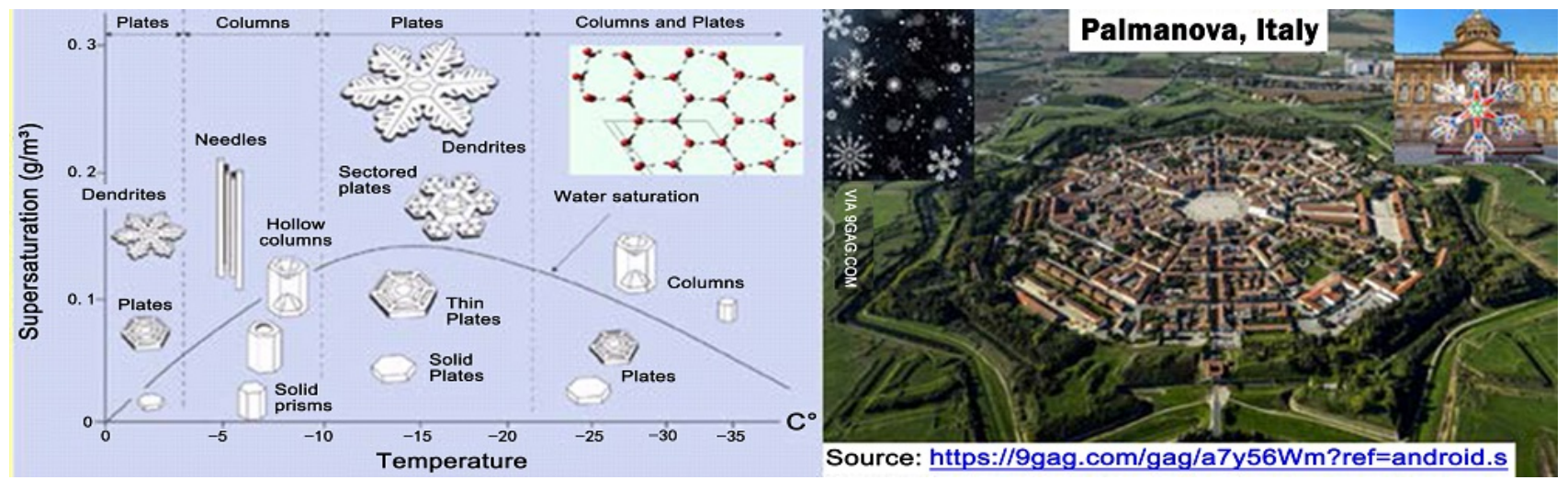

Figure 50. City plan inspired by snowflake

The Eastgate Center is a shopping center and Zimbabwe architect was designed by Mick Pearce. Designed to be ventilated and cooled by entirely natural means, it was probably the first building in the world to use a natural cooling system. Glass office blocks are needed heating in the winter and cooling in the summer. Artificial air-conditioning systems are high-maintenance, and Zimbabwe has the additional problem that spends foreign exchange reserves. Mick Pearce proposed an alternative approach. The typical daily temperature swing is 10 to $14^{\circ} \mathrm{C}$, and can make a passive cooling system. The building must be very carefully designed. It is planned that no direct sunlight must fall on the external walls at all and the north façade [direction of summer sun] window-to-wall area must not exceed $25 \%$. It is required a 
balance between artificial and external light to minimize energy consumption and heat gain. As the wind blows, hot air from the main chambers is drawn out of the structure, opening or blocking tunnels to control air flow. In 2003 Pearce was awarded the Prince Claus Award for culture and development.
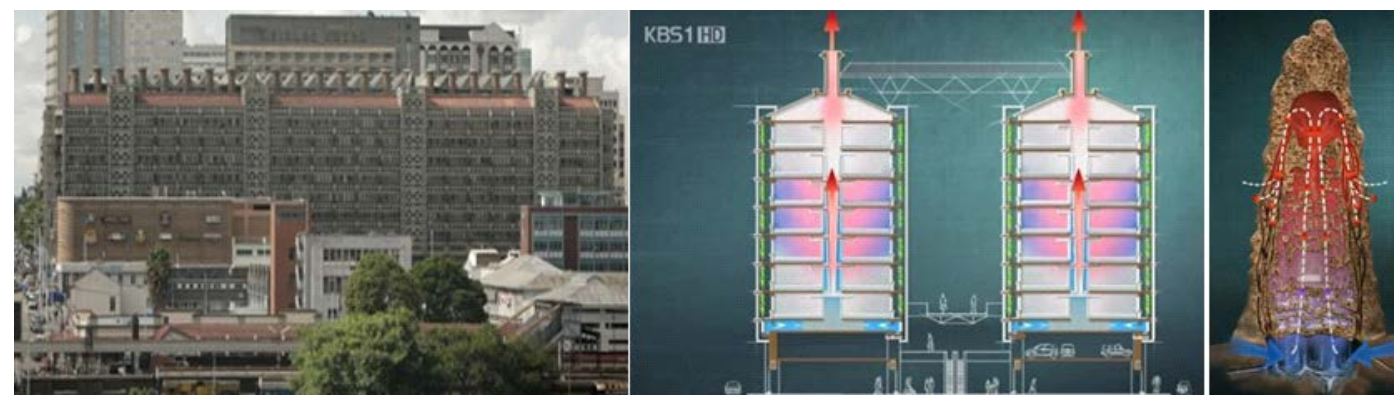

Source: https://ehp.niehs.nih.gov/pdf-files/2013/Jan/ehp.121-a18_508.pdf

Figure 51. Eastgate Shopping Center

Situated in Hamburg, Bio-Intelligent Algae house is the first algae powered building in the world. Five-story passive house designed two differently façade types. The sides of the building that face the sun have a outer shell. Microalgae are produced energy to supply the building. The façade collects energy by absorbing the light that is not used by the algae and generates heat. The building was Prize winner in the competition 'Land of Ideas' in 2013.
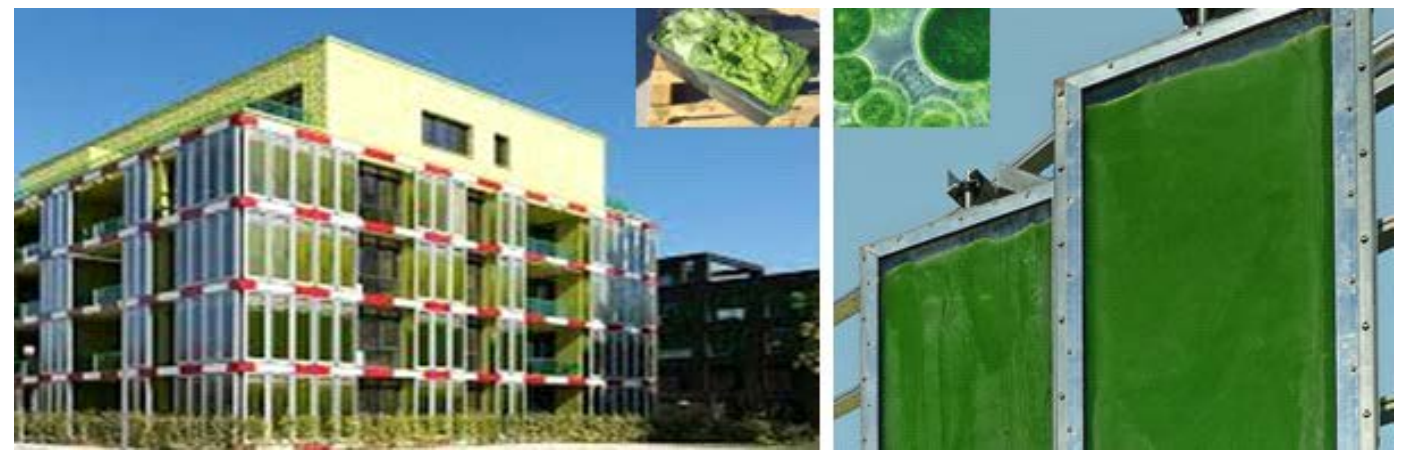

Source: http://www.buildup.eu/en/practices/cases/biq-house-first-algae-powered-building-world

Figure 52. Bio-intelligent Algae house

Recently, natural inspiration buildings are designed with dynamic and complicated structures unlike conventional box buildings. They are buildings that can produce electricity by using wind and sunlight and are capable of self-sufficiency. It is an eco-friendly building designed as energy zero building. Recent innovative designs are famous for Cobra Tower, Diamond Tower, DNA Tower, Crescent Tower and Oxygen eco-tower.

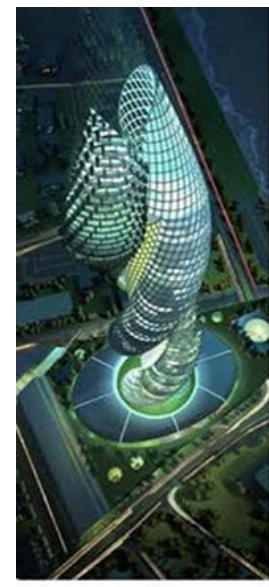

Cobra Towers in Kuwait

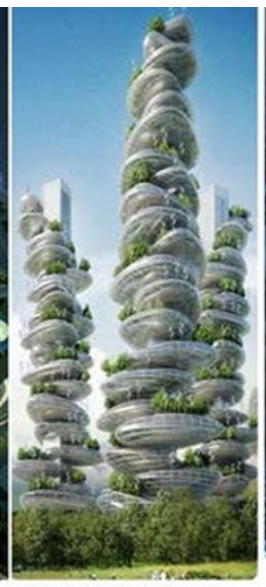

Futuristic Architecture, Asian

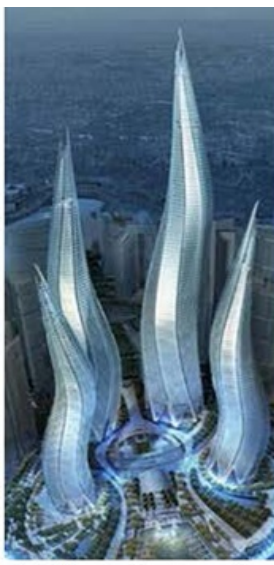

Dubai Towers, The Lagoons in Dubai, UAE, by Thompson...

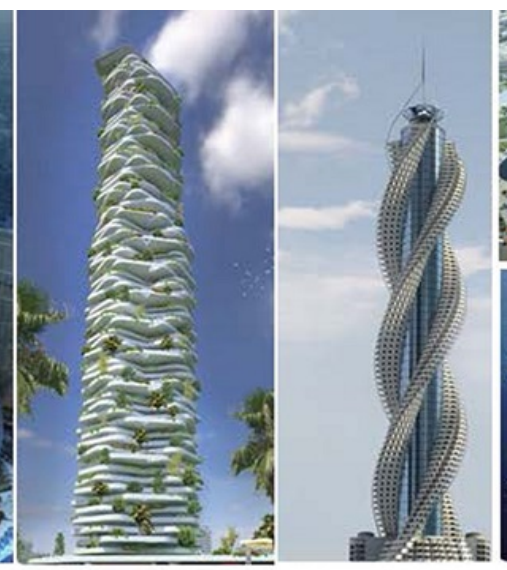

Oxygen Eco-tower - photo

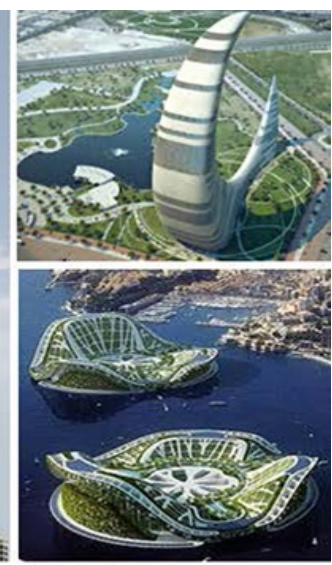

Futuristic floating cities

Figure 53. Nature-inspired architecture for innovative building design 


\section{Nature-inspired Technology}

Nature reveals unlimited adaptations and evolutions for the creation of organisms and mechanisms. Biomimicry imitates nature to help solve difficult problems and achieve innovation by creating wise and sustainable designs in more diverse fields. Architects can achieve great effects by merging biomimicry into their research or work process of building design. Scientists are working on making solar power using plants' photosynthesis processes, and they have developed new adhesives by getting ideas about the adhesion of shellfish such as mussels. The nature inspired designs and technologies are a way of observing the natural world to identify new ideas that may enable us to create mechanisms and processes that are sustainable for natural ecosystem.

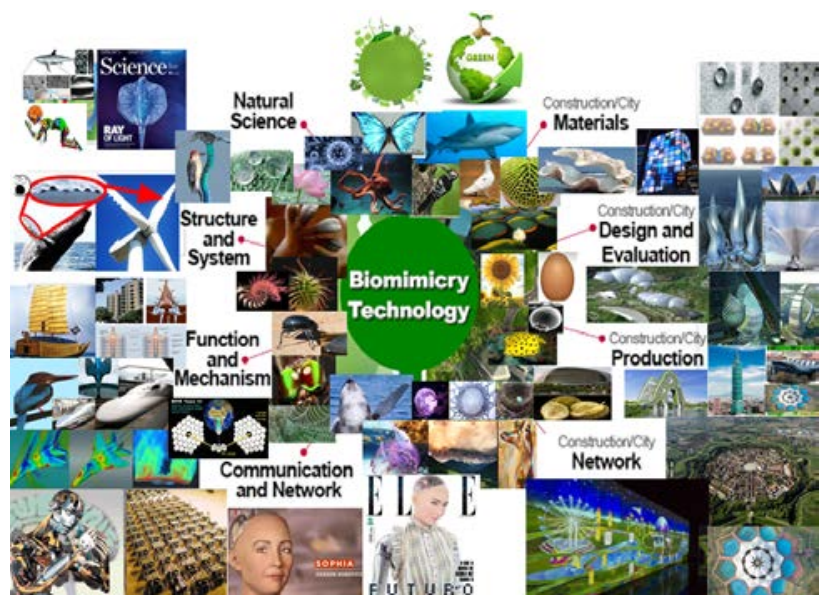

Figure 54. Nature-inspired biomimicry architecture and technology

The research on biomimetic robot imitating animals such as lizards, butterflies, cheetahs, elephants and whales has been actively conducted in many countries around the world. The bio-inspired robot is a new robot inspired by real biological systems. The Korea SNU biorobotics lab has developed biologically soft mechanisms and robots aimed at developing innovative ways to create movements without rigid joints and rigid links. Scientists are interested in a soft, wearable robot that needs a biologically inspired design to create a way to effectively help move people with disabilities. Stanford University Lab invented a lizard robot. It is a lizard robot that can climb a window thanks to a special suction cup. These suction cups are not usually adhesives and are made up of mini-particles that can stick to the material using van der Waals forces. The MIT Biomimicry Laboratory is developing disaster response robots by utilizing the inspirations from animals. The researchers are developing new robotics and leading to advanced mobile robots that can save lives in dangerous situations. The embodiment of such innovations are Stickybot that employs the synthetic adhesive inspired by geckos, and the MIT Cheetah, designed after the fastest land animal. The Institute for Computational Design (ICD) at Stuttgart University was developed Spiderbot. The research aims to significantly extend the scope of robotic fabrication for carbon fiber architecture explored in several building prototypes by the two institutes, and to display new production processes for filament structures. The Festo engineers was developed BionicANTs with the delicate anatomy of the natural ant.

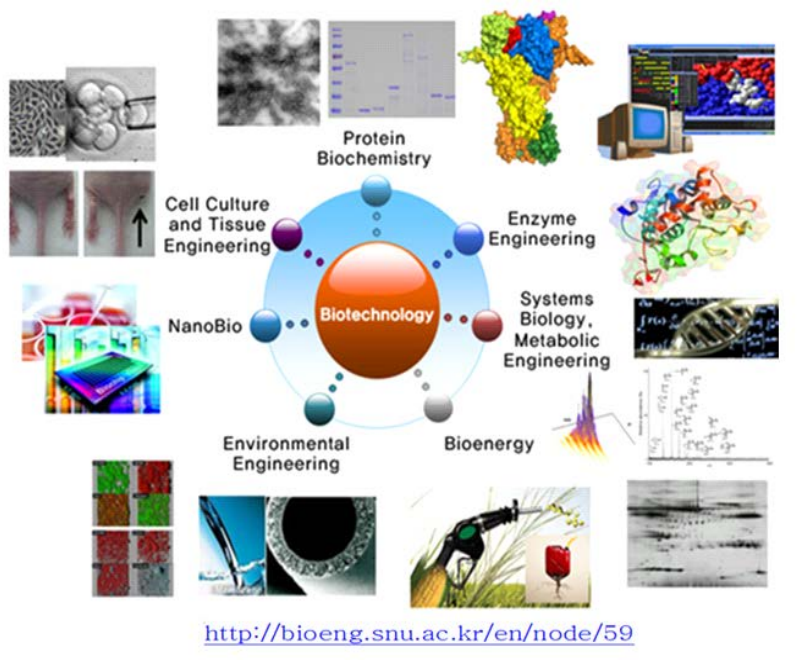

Figure 55. Nature-inspired biotechnology

The cooperative behavior of ants has also been transferred to the world of technology using complex control algorithms. Japan Softbank was developed a human recognition robot, Papper. Pepper has the advantage of being a humanoid robot to better communicate with humans. Biometrics technology is one of the biggest growth areas for biomimicry in recent years. Financial, healthcare, and cell phone become the major industries in the biometrics market, and fingerprint, iris, and voice recognition are the most commonly used biometrics. Humans are the most advanced creatures of the nature. The humanoid robots will be the most advanced creatures of humans. Future robots will hopefully be the most ideal assistants to human beings. Robot, Sopia is likely to feel absolutely terrifying.

\section{Conclusions}

Human life is surrounded by nature and cannot be separated from nature. When planning and constructing for the new cities, it is important to find how to satisfy our yearning for harmonious interactions with nature. With the beginning of man-made environments, an architect has inspired from nature in order to get new ideas.

(1) The nature inspirations can be new strategies for achieving new technologies for solving human problems. Inspiration of nature can be a new strategy for achieving new technologies to solve human problems. The environmental pollution of the earth is 
threatening the survival of mankind. It is important not to go against the principle of sustainable nature and the cyclic structure. The earth's environment is destroyed by the numerous materials created by humans, and numerous creatures are disappearing. It is very important to produce and use natural materials that can be regenerated as much as possible.

(2) Nature inspired models are a field of science that studies nature elements and then imitates or takes inspirations for innovative things. Nature can be an ecological standard to judge the rightness of human life. The principles of nature are more sophisticated than technologies developed by humans. Nature is creating technologies that modern science cannot understand. Humans can create new ideas and technologies from these natural mysteries.

(3) During 3.8 billion years of changes and evolutions of nature, nature has learned what is optimal and what is appropriate. Nature is a laboratory in which life has evolved the adaptations of its diverse environments. The organisms of nature are the results that changed a sustainable equilibrium conditions in their environments in the Earth.

(4) Visual inspirations of buildings are used to create designs or engineering systems that share the visual appearance of nature. Unlike conventional box-shaped buildings, natural inspiration architecture is designed with a special natural design concept, so it gives a more beautiful and friendly feeling. However, if the shape becomes too free and complex, the design and construction costs become too high. Many buildings mimicking the shape of nature are playing a role of landmark in the area and the formability is emphasized so that it is uneconomical in terms of usability and maintenance.

(5) Conceptual inspirations are the use of the knowledge found in rules, principles, or patterns. Computation inspirations such as algorithmic bio-mimicry are searching through nature to find algorithms like evolutionary technologies such as generative representations.

\section{Acknowledgements}

(1)This research was supported by a grant (17AUDP-B100343-03) from Architecture \& Urban Development Research Program funded by Ministry of Land, Infrastructure and Transport of Korean government.

\section{REFERENCES}

[1] Janine M. Benyus, Biomimicry: Innovation Inspired by Nature , ISBN0-06-053322-6, 1997

[2] https://www.webdesignerdepot.com/2009/08/17-techniques -for-creating-designs-inspired-by-nature/

[3] https://ko.wikipedia.org/wiki/\%EC\%83\%9D\%EC\%B2\%B4 \%ЕВ\%АA\%А8\%ЕВ\%В0\%А9

[4] https://new.usgbc.org/leed

[5] https://www.curbed.com/2014/3/7/10135008/chinas-latestbizarre-building-is-a-giant-ethereal-lotus-flower

[6] https://en.wikipedia.org/wiki/Qizhong_Forest_Sports_City_ Arena

[7] NISA 2016 manual, Crane software

[8] Park, K., Lee, S. and Lee, D. (2015), A Study on the Structural System of Flexible Large Span Spatial Roofs Using Steel Cables, Journal of The Residential Environment Institute of Korea, Vol.13(No.4), pp.393-404

[9] Park, K. and Lee, D. (2016), A Study on the Nature Inspiration Design of Eco-friendly Spatial Buildings, Journal of The Residential Environment Institute of Korea, Vol.13(No.5), pp.1-29

[10] Park, K. and Lee, D. (2016), Mechanical Characteristics of Cable Truss Roof Systems, Journal of Korean Association for Spatial Structures, Vol.16(No.2), pp.89-96

[11] Park, K. and Lee D. (2016), Mechanical Behavior of Cable Net Structures Considering Sag Ratio, Journal of Korean Association for Spatial Structures, Vol.16(No.3), pp.47-58

[12] Park, K., Lee, D. and Kwun, T. (2016), Mechanical Characteristics of Large Span Spoke Wheel System, International Association for Spatial Structures (IASS), N. 1341

[13] Park, K., Lee, D. and Lee, S. (2016), A Nature Inspired Design Philosophy of Spatial Structures, International Association for Spatial Structures (IASS), N. 1342

[14] http://beautiful-amazing-nature.blogspot.kr/2013/05/aweso me-infosys-building-kuwait.html

[15] http://vincent.callebaut.org/

[16] http://www.rexresearch.com/hilbertzbiorock/hilbertz.html

[17] https://www.thebalance.com/beijing-s-bird-s-nest-stadium2340205

[18] http://www.buildup.eu/en/practices/cases/biq-house-first-al gae-powered-building-world

[19] http://www.buildup.eu/en/practices/cases/biq-house-first-al gae-powered-building-world

[20] https://archinect.com/toyo_ito 